\title{
Prediction of Seasonal Meteorological Drought Onset and Termination over the Southern Great Plains in the North American Multimodel Ensemble
}

\author{
Richard SEAGER, JENNifER NAKAMura, AND MingFAng Ting \\ Lamont-Doherty Earth Observatory, Columbia University, Palisades, New York
}

(Manuscript received 28 January 2020, in final form 30 June 2020)

\begin{abstract}
The predictability on the seasonal time scale of meteorological drought onsets and terminations over the southern Great Plains is examined within the North American Multimodel Ensemble. The drought onsets and terminations were those identified based on soil moisture transitions in land data assimilation systems and shown to be driven by precipitation anomalies. Sea surface temperature (SST) forcing explains about a quarter of variance of seasonal mean precipitation in the region. However, at lead times of a season, forecast SSTs only explain about $10 \%$ of seasonal mean precipitation variance. For the three identified drought onsets, fall 2010 is confidently predicted and spring 2012 is predicted with some skill, and fall 2005 was not predicted at all. None of the drought terminations were predicted on the seasonal time scale. Predictability of drought onset arises from La Niña-like conditions, but there is no indication that El Niño conditions lead to drought terminations in the southern Great Plains. Spring 2012 and fall 2000 are further examined. The limited predictability of onset in spring 2012 arises from cool tropical Pacific SSTs, but internal atmospheric variability played a very important role. Drought termination in fall 2000 was predicted at the 1 -month time scale but not at the seasonal time scale, likely because of failure to predict warm SST anomalies directly east of subtropical Asia. The work suggests that improved SST prediction offers some potential for improved prediction of both drought onsets and terminations in the southern Great Plains, but that many onsets and terminations will not be predictable even a season in advance.
\end{abstract}

KEYWORDS: North America; Teleconnections; Drought; Hydrometeorology; Seasonal forecasting

\section{Introduction}

According to the National Oceanic and Atmospheric Administration's National Center for Environmental Information (NOAA/NCEI) the average cost of drought in the United States is $\$ 9.6$ billion per year (NOAA/NCEI 2020a) making it the second most costly weather and climate phenomenon in the past three decades (NOAA/NCEI 2020b). The costs of drought are primarily in the agriculture sector, but drought also impacts power generation, recreation, and numerous other parts of the national economy. Often not recognized, drought also has serious impacts on the mental health of farming families and people in agricultural communities with long-lasting effects [see U.S.-based review by Vins et al. (2015)]. Improved understanding and forecasting of drought at least provides the possibility of improved anticipation of, and adaptation to, drought conditions with potential benefits for people and society.

Understanding the physical causes of droughts in North America, and the relative roles of ocean driving by sea surface temperature (SST) anomalies and internal atmosphere variability has advanced considerably over the last two decades [see recent review by Seager and Hoerling (2014)]. The role of land surface-vegetation-atmosphere interactions in drought evolution is also receiving increased attention (e.g., Sun et al. 2015; Mo and Lettenmaier 2016; Otkin et al. 2016; Basara and Christian 2018; Ford et al. 2017; Basara et al. 2019). However, when a drought is occurring those impacted always ask when will it end? Alternatively, when drought is absent wise managers

Corresponding author: Richard Seager, seager@ldeo.columbia.edu of water, land and ecosystem resources want to know the likelihood of drought in the near future. Nonetheless, the causes of drought onset and termination (DO\&T) have received limited attention (Karl et al. 1987; Mo 2011; Maxwell et al. 2013, 2017) compared to the causes of drought itself. The causes of DO\&T are inherently a more difficult problem than the causes of the drought itself. Since DO\&T refers to a change over time it brings in higher-frequency components of the climate system that may be highly random in time and difficult to predict. In contrast, drought, as measured by soil moisture, integrates precipitation less evapotranspiration (ET) plus runoff $(R)$ over time and, hence, records lowerfrequency components of the climate system and can be quite closely related to SST variations (Schubert et al. 2004a,b; Seager et al. 2005; Herweijer et al. 2006; Seager and Hoerling 2014).

In a recent observational study, Seager et al. (2019, hereafter SNT) advanced understanding of DO\&T. They identified coherent continental-scale patterns of seasonal time scale soil moisture change over time associated with precipitation anomalies that were themselves associated with hemispheric-scale circulation anomalies. The results showed the southern Plains to be a geographic center of these large-scale patterns. SNT then developed criteria for drought onset and termination in the southern Plains using three land data reanalyses. An important result of SNT was that seasonal time scale soil moisture DO\&T was driven by precipitation anomalies and that there were no clear driving roles for ET (influenced by temperature anomalies) nor $R$ in creating drought onset or termination. SNT used the different land data reanalyses to identify three onsets and terminations 
in the post-1979 period and determined the associated continental and hemispheric scale anomalies in precipitation, circulation, water vapor transports and SSTs. All onsets and terminations were associated with northerly and southerly flows, respectively, and associated anomalous moisture exports and imports. However, SNT also found that the flow anomalies occurred within a variety of hemispheric scale circulation anomaly patterns. SNT further found that these DO\&Ts and driving circulation anomalies were not consistently related to SST anomalies that might provide predictability on seasonal time scales. The clear exception was fall 2010 when La Niña conditions drove drying over the southern Plains and induced drought onset, a case that has been studied before (e.g., Seager et al. 2014). According to SNT, other onsets and terminations of drought were most likely driven by internal atmosphere variability. Their argument was essentially that while droughts, as phenomena that integrate surface moisture fluxes over time, can be driven by ocean variations and hence be potentially predictable on a seasonal to interannual time scale, their onsets and terminations are likely controlled by internal atmosphere variability and fall between the initial value and ocean boundary condition sources of predictability.

However, SNT was a purely observational study. Here we report on how well DO\&Ts are forecast in the operational seasonal predictions systems of the National Multimodel Ensemble (NMME; Kirtman et al. 2014). These systems forecast SST from imposed initial conditions. Several of the models also initialize soil moisture anomalies but not vegetation anomalies (e.g., leaf area index). Predictability of precipitation on the month to seasonal time scale can arise from the prescribed initial values and the successful prediction of SST and how it influences atmospheric circulation and then precipitation.

For the case of DO\&T, the potential role of SST anomalies is clear since they can persist or evolve in a way that drives circulation anomalies over the southern Great Plains that lead to diminished or enhanced precipitation and favoring drought onset or termination. Both a cold (warm) tropical Pacific and warm (cold) tropical North Atlantic favor decreased (increased) precipitation over the southern Plains (Schubert et al. 2009; Kushnir et al. 2010; Nigam et al. 2011; Seager et al. 2014; Pu et al. 2016). To simulate this, the models must need to forecast the SST, the connection of that to diabatic heating in the atmosphere and the driving of Rossby waves and then the connection of circulation anomalies to precipitation over the Plains. Models can have biases and inadequacies in each of these steps that connect remote SSTs to local precipitation. As the forecast evolves the model must also simulate how interactions between the land surface and the boundary layer further influence how precipitation evolves over the forecast period (Basara et al. 2019).

The role of soil moisture initial conditions in the context of DO\&T is interesting to consider. DO\&Ts are defined here in terms of soil moisture shifts of sufficient amplitude from the normal or wet to the dry tercile (onsets) and from the dry to the normal or wet tercile (terminations) of the historical soil moisture distribution. For onsets, it is unlikely that the seasonal precipitation declines were impacted by the generally weak soil moisture anomalies at the start of the season. For terminations, the dry soils could either favor drought persistence if the soil moisture-precipitation feedback is positive or favor termination if the feedback is negative (dry soils lead to enhanced precipitation). Quantifying feedbacks between soil moisture, ET, and precipitation are confounded by persistence in soil moisture, atmosphere circulation (e.g., persistent anomalies driven by SSTs) and precipitation. Tuttle and Salvucci (2016), taking care to account for persistence in an observational study, suggest that the soil moisture-precipitation feedback is positive in the arid to semiarid inland regions of North America and negative in the humid east. This could be explained in terms of the varying roles of energy and water limitations on ET, the varying contributions of ET and moisture convergence to precipitation, and the coupling between surface energy and water fluxes and boundary layer and precipitation processes [see discussion and references in Tuttle and Salvucci (2016) and the recent review by Miralles et al. (2019)]. Notably, Tuttle and Salvucci (2016) identify the Great Plains as a region that is transitional between positive and negative soil moisture-precipitation feedbacks and hence has weak feedbacks. Looking solely at the case of afternoon summertime convection in the southern Great Plains, Welty and Zeng (2018) found no overall driving of precipitation by morning soil moisture due to canceling effects of enhancement and suppression for high or low moisture convergence regimes. In contrast to this lack of evidence of strong soil moisture-precipitation coupling in the southern Great Plains, Seager and Hoerling (2014) identify this as the region of North America with the highest ratio of SST-forced to total precipitation variability. Therefore, here we focus on the role of SST-based predictability of DO\&T.

In the following section, we describe the data used and the methods, followed by results in section three and discussion and conclusions to follow. It is concluded that potential for seasonal prediction of DO\&Ts is modestly more than SNT thought based on observations alone.

\section{Data and methodology}

In the observational study of SNT, the definition of DO\&Ts was based on soil moisture transitions using data from the land model reanalyses within the North American Land Data Assimilation Two (NLDAS-2) dataset (Xia et al. 2012a,b). The land models in NLDAS-2 are driven by observed and reanalyzed surface air meteorology and precipitation. Soil moisture is not available for most of the models that participated in NMME, and hence here we focus on precipitation, that is, meteorological drought. Since SNT showed that DO\&Ts were driven by precipitation anomalies, the work, therefore, focuses on the predictability of the driving mechanisms of DO\&Ts in recent history. We will analyze the DO\&Ts identified by SNT based on cross-NLDAS-2 model agreement on soil moisture transitions. In SNT DO\&Ts were identified as seasonal transitions in standardized soil moisture anomaly of at least one standard deviation magnitude. Onsets are from the middle or upper tercile to the lower tercile, and terminations from the lower tercile to the middle or upper tercile of the statistical 
distribution of anomalies. As such, since droughts can begin or end over seasonal or longer time scales, the DO\&Ts do not need to come in pairs. These were the only six seasonal time scale DO\&Ts in the post-1979 record for which there was agreement across the NLDAS-2 models. The DO\&Ts are

- drought onsets: October-December (OND) 2005, OND 2010, April-June (AMJ) 2012 and

- drought terminations: January-March (JFM) 1990, OND 2000, June-September (JAS) 2006.

The DO\&Ts are spread over all four seasons and it would be reasonable to expect differing levels of predictability given the greater influence over North America of remote tropical Pacific SST anomalies in the cold season than in the warm season (Kumar and Hoerling 1998) and the expected greater role of land surface feedbacks in the warm season than the cold season (Koster et al. 2004; Miralles et al. 2019). The work will assess how well the precipitation anomalies that SNT showed drove these DO\&Ts were predicted by NMME models at lead times from 0.5 to 4.5 months.

\section{a. Observations}

The observed precipitation data over the southern Great Plains are from daily Climate Prediction Center gauge observations using the topographic adjustment method of the PRISM group (Daly et al. 2000). These are the precipitation data used to drive the NLDAS-2 land models and were obtained from https://das.gsfc.nasa.gov/nldas/ nldas-2-forcing-data. To examine the large-scale context of the DO\&Ts, we use geopotential heights and SSTs from the National Centers for Environmental Prediction-National Center for Atmospheric Research (NCEP-NCAR) Reanalysis (Kistler et al. 2001; obtained from https://iridl.ldeo.columbia. edu/SOURCES/.NOAA/.NCEP-NCAR/.CDAS-1/.MONTHLY/ ?Set-Language $=\mathrm{en}$ ) and precipitation over land and sea from the Global Precipitation Climatology Project (GPCP) version 2.3 (Huffman et al. 1997; obtained from https://iridl. ldeo.columbia.edu/SOURCES/.NASA/.GPCP/.V2p3/.CDR/ index.html?Set-Language $=\mathrm{en}$ ).

\section{b. The North American Multimodel Ensemble}

The NMME is an ensemble forecasting system of coupled models from U.S. and Canadian institutions. We analyzed seven NMME models that provided data for precipitation, SST, and 200-hPa geopotential heights and covered the period from 1982 to the present. Data were obtained from the NMME database at the International Research Institute for Climate and Society at https://iridl.ldeo.columbia. edu/SOURCES/.Models/.NMME/. The models within the NMME have varied over time. Examining the IRI database we found that for our purposes we could use the following models (ensemble size in parentheses): NASA GEOS (4), NASA GMAO (10), GFDL CM2.1 (10), GFDL 2.5 FLORA06 (12), GFDL 2.5 FLOR-B01 (12), COLA CCSM3 (6), and COLA CCSM4 (10). We consider forecast of seasonal means at lead times of 0.5-4.5 months, i.e., for AMJ 2012, which was a drought onset, we consider forecasts for AMJ 2012 initialized on 1 April 2012 (0.5-2.5 months lead time),
1 March 2012 (1.5-3.5 months lead time), and on 1 February 2012 (2.5-4.5 months lead time).

To define precipitation anomalies within the NMME forecasts, account must be taken that, as the forecast progresses in the coupled model, the atmosphere-ocean state will evolve influenced by the specified initial conditions and by a possible drift of the model back to a preferred climatology. Hence anomalies for the same month at different lead times must be relative to different "climatologies." We define the anomaly, say for precipitation $P^{\prime}$, for calendar month $m$, in year $n=$ nyr at lead time $l$ as

$$
P^{\prime}(m, \mathrm{nyr}, l)=P(m, \mathrm{nyr}, l)-\sum_{n=1}^{N} P(m, n, l),
$$

where $N$ is the number of years in the NMME data. Hence, climatologies are defined over all years of forecasts for each specific lead time.

\section{Results}

a. The influence of SST on monthly time scale precipitation over the southern Great Plains

Essential to the assessment of how well seasonal time scale DO\&Ts can be predicted over the southern Great Plains is the extent to which SSTs, which are potentially predictable, influence seasonal precipitation. Since the SSTs within the NMME data are forecast, the best way to assess this is to look at the 0.5-month lead time (i.e., the forecast of the following month from the first day of the month) during which the forecast SST, due to the longer-than-monthly time scale of SST anomaly evolution, will deviate least from the observed SST. We combine these 0.5 -month lead time forecasts into seasonal means. This will emphasize seasonal time scale processes over the random atmospheric variability that will be more important in the monthly data. Figure 1 plots the observed seasonal mean precipitation anomalies for the southern Great Plains together with, for each model, the ensemble mean and the spread (from minimum value to maximum value) across the ensemble members. Also, the last panel in Fig. 1 shows (i) the multimodel mean and (ii) the spread across-model ensemble means and (iii) the spread across models and ensemble members. Skill is quite variable across the model ensemble ranging from a correlation coefficient with the ensemble mean from 0.11 (COLA CCSM3) to 0.54 (COLA CCSM4). The multimodel mean averages across the maximum number of realizations of internal variability and across model biases and errors and is expected to provide the best estimate of the SST-forced signal and, hence, the best forecast of the real world on seasonal time scales. It provides a correlation of observed and modeled seasonal mean precipitation of 0.47 . In an unusual occurrence, therefore, one model has a higher skill than the multimodel mean. In sum, according to these models, about a quarter of the variance of precipitation is caused by SST variations and hence potentially predictable on the seasonal time scales of SST persistence, evolution and predictability. The times of DO\&T are also shown in Fig. 1. The three drought onsets were driven by seasonal precipitation declines that were among the most 
Seasonal S. Plains Precip, Observed (black), Model (red), Model Ensemble (pink)
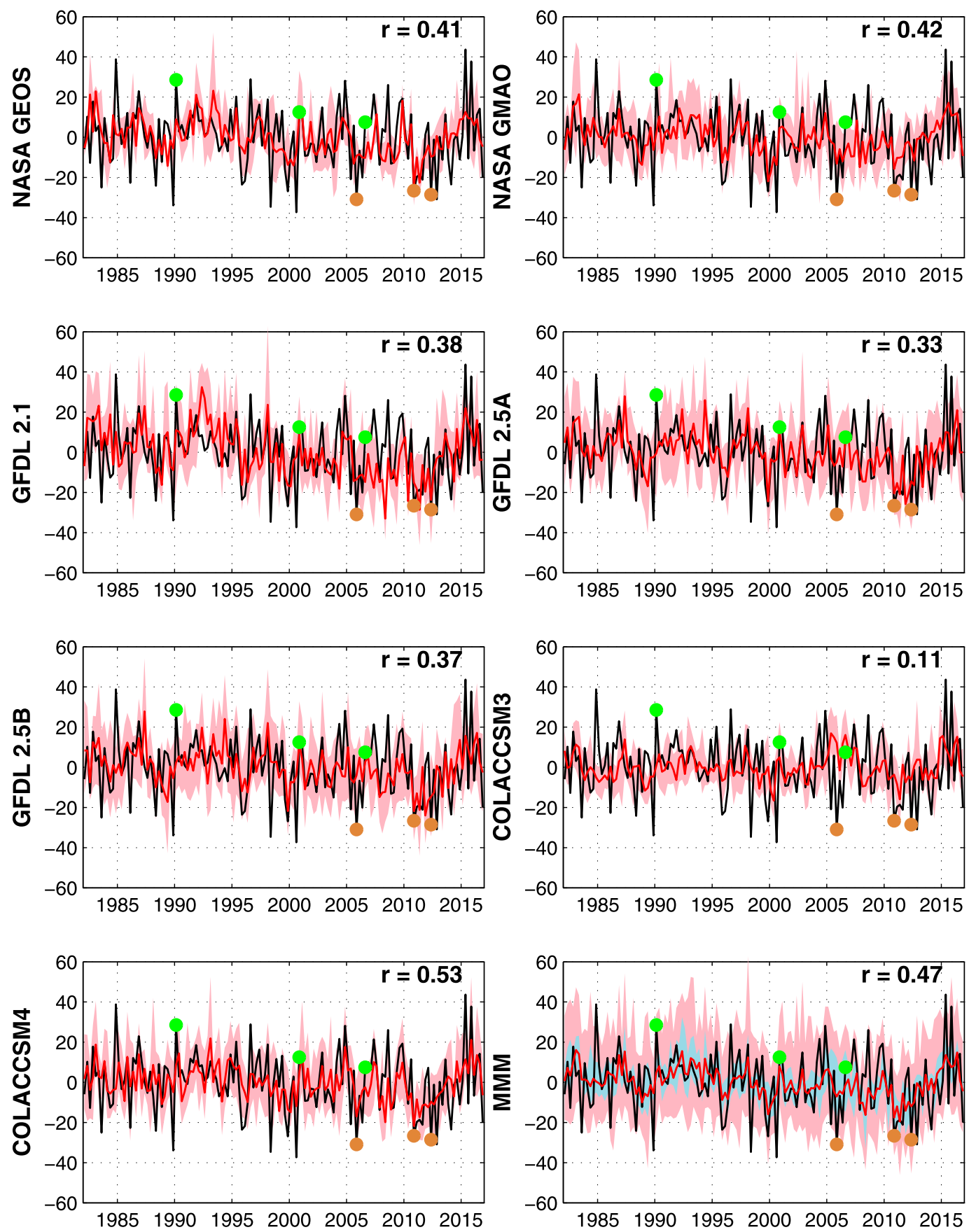

\section{Green Dot (Drought Termination), Brown Dot (Drought Onset), Model Mean (blue)}

FIG. 1. Observed and modeled seasonal precipitation anomalies $\left(\mathrm{mm} \mathrm{month}^{-1}\right)$ over the southern Great Plains for individual NMME models and the multimodel mean at the bottom right. Modeled values are from monthly 0.5-month lead time forecasts formed into seasonal means. Ensemble spread for each model is shown as pink shading around the red line. For the multimodel mean the blue-gray shading is the spread of the ensemble means of the individual models, and the pink shading is the spread of all the ensemble members across all the models. Drought onsets and termination identified based on soil moisture transitions in NLDAS-2 land reanalyses are indicated as brown and green dots, respectively. 

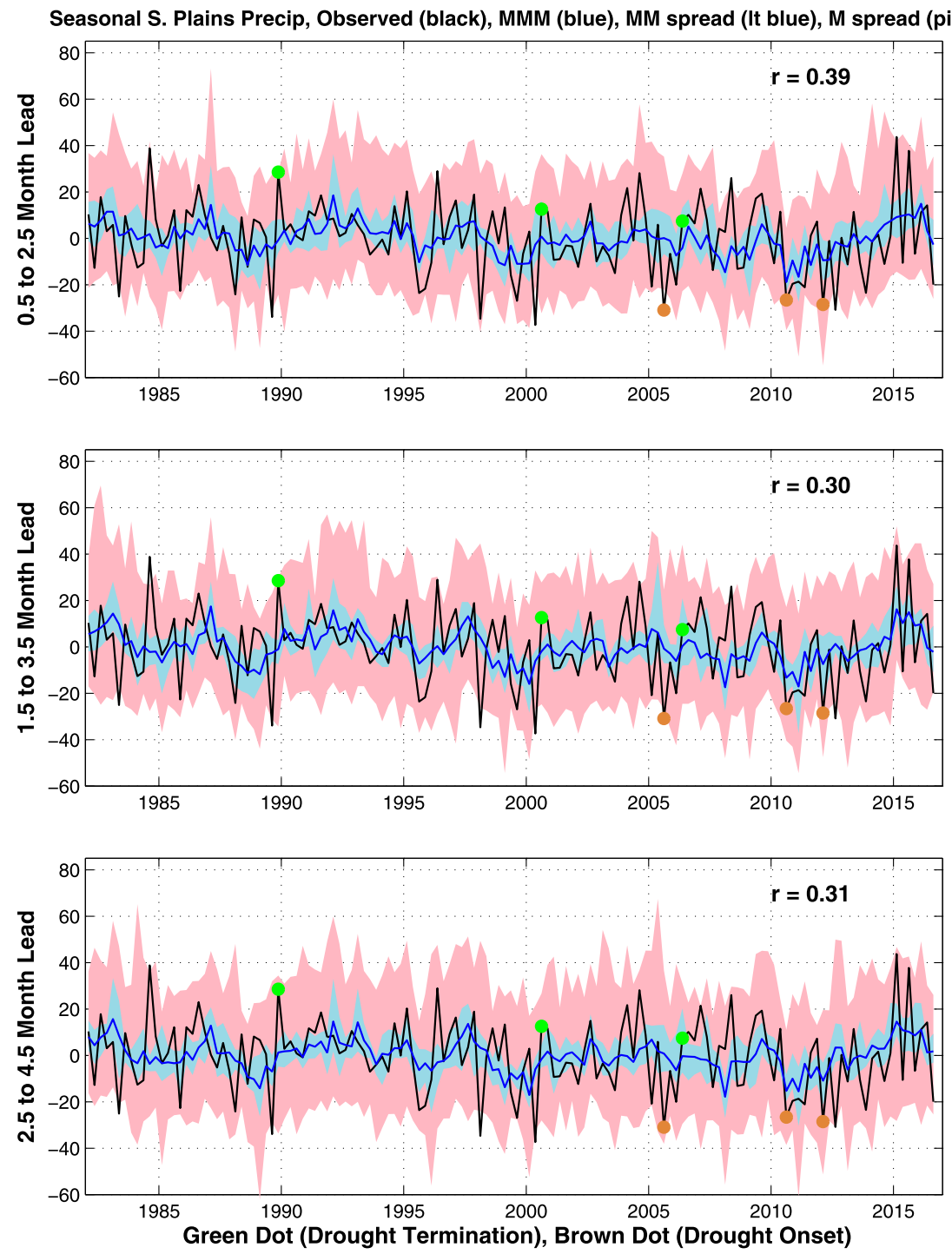

FIG. 2. Observed and NMME ensemble forecasts for (top) $0.5-2.5$, (middle) $1.5-3.5$, and (bottom) 2.5-4.5 months lead times of seasonal precipitation anomalies (mm month ${ }^{-1}$ ) for the southern Great Plains. The blue curve is the multimodel ensemble mean, the blue shading is the spread of individual model ensemble means, and the pink shading is the spread across all model ensemble members. Brown and green dots mark drought onsets and terminations, respectively.

extreme in the record but, notably, two of the drought terminations were driven by only modestly wet seasonal precipitation anomalies.

\section{b. Forecasts at various lead times of seasonal precipitation over the southern Great Plains}

Figure 2 shows the time series of observed and forecast precipitation at lead times of $0.5-2.5,1.5-3.5$, and $2.5-$ 4.5 months from the NMME ensemble. The model forecasts are shown as the multimodel mean of model ensemble means with both the spread across the model ensemble means and the spread across the entire multimodel ensemble members shaded. As expected, the correlation of the observed and multimodel mean forecast is lower for these lead times $(0.39$, $0.30,0.31$ for increasing leads) than for the 0.5 -month lead time (0.47). This decrease must be due to errors developing in the SST forecasts.

\section{c. Forecasts at various lead times of DO\&Ts over the southern Great Plains}

The analysis to date has considered the general predictability of precipitation over the southern Great Plains so next we turn to forecasts of DO\&Ts. It is reasonably clear that predictability drops as lead time increases. Hence, Fig. 3 presents a summary plot of prediction of DO\&Ts at the seasonal time scale of lead times of $0.5-2.5$ months. For the 


\section{Southern Plains Seasonal Precipitation Anomaly}
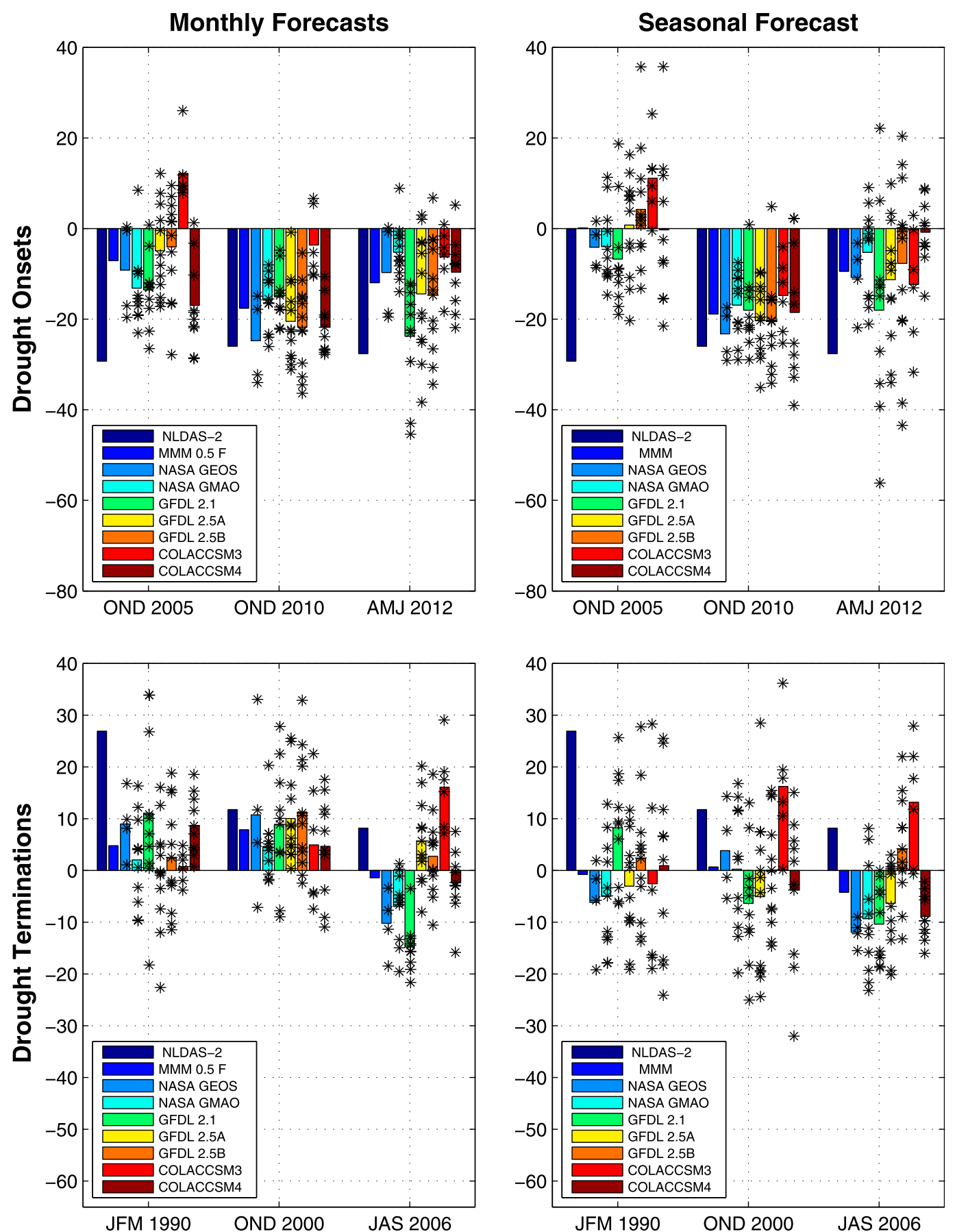

FIG. 3. Actual and NMME forecast precipitation anomalies ( $\mathrm{mm} \mathrm{month}^{-1}$ ) during drought (top) onsets and (bottom) terminations over the southern Great Plains for (left) the seasonal means of 0.5-month lead time forecasts and (right) the shortest (0.5-2.5 months) lead time seasonal predictions. The left-hand bar shows the observed anomaly from NLDAS-2, and the bar to its immediate right shows the multimodel mean with the individual models to the right. The asterisks show the ensemble members for the individual models. 
seasonal predictions, shown in the right column of Fig. 3, for example, prediction of AMJ 2012 is from 1 April 2012. For reference we also show in the left column of Fig. 3 the monthly time scale predictions. In this case, for example for AMJ 2012, we show the average of 0.5 -month lead time predictions from 1 April, 1 May, and 1 June 2012. These monthly predictions assess how well DO\&Ts might be expected to be predicted if the SST anomalies were very well predicted. For drought onsets, OND 2010 stands out as being highly predictable on the seasonal time scale. All but 3 of 64 ensemble members predict drier than normal conditions and all ensemble means predict significantly drier than normal conditions with remarkable consistency across models. The multimodel ensemble mean predicts a precipitation decline that is about three-quarters of the observed value. In contrast, the drought onset in OND 2005 is not predicted at all and one model (CCSM3) errs on the wet side. AMJ 2012 is an interesting case where all model ensemble means predict a season ahead drier than normal conditions as does the multimodel ensemble mean, though less than half of the observed value. AMJ 2012 was not a case that the authors of SNT thought to be potentially predictable in terms of SST, because tropical Pacific and Atlantic SST anomalies were quite weak at that time, and hence we will examine this drought onset in more detail below. In contrast to the drought onsets, none of the drought terminations were predicted on the seasonal time scale in the multimodel ensemble.

The seasonal means of 0.5 -month lead time monthly forecasts (Fig. 3, left column) are consistent with the successful seasonal forecasts of drought onset for OND 2010. They also suggest that the drought onset in AMJ 2012 would have been more confidently predicted, and the drought onset in OND 2005 and the drought termination in OND 2000 might have been predicted, if the SSTs had been better predicted at the seasonal time scale.

Figure 4 shows the continental scale precipitation anomalies associated with the observed drought onsets and the predictions. For each observed onset, there was a strong negative precipitation anomaly centered over the southern Plains with wetter than normal conditions somewhere over the west coast and over northeast North America. Especially for OND 2010, and to some extent for AMJ 2012, the forecasts can pick up this continental-scale rearrangement of precipitation at leads times out to 2.5-4.5 months. Over western North America and the southern Plains this pattern is suggestive of that which can be induced by a cooler than normal tropical Pacific Ocean (Seager et al. 2014). In contrast, a similar continental-scale pattern of precipitation anomalies in OND 2005 was not predicted by the models at all.

Figure 5 shows the precipitation anomalies for the three drought terminations. As expected, the continental scale patterns are to some extent the opposite of those for drought onsets, with wet conditions over the southern Great Plains accompanied by drier than normal conditions over all or part of the American West. The pattern for JAS 2006 is rather diffuse consistent with SNT. Remarkably, in the multimodel ensemble mean, none of these precipitation patterns were predicted at any lead time.

What gives rise to the greater potential predictability of drought onsets than of drought terminations? In Figs. 6 and 7 we show the hemispheric precipitation and $200-\mathrm{hPa}$ height anomalies to examine the large-scale circulation context of the DO\&Ts. (As shown in SNT, during DO\&Ts, the low-level flow and moisture advection are essentially in the same direction but eastward shifted relative to the upper-level flow). In the observations the drought onsets are all associated with wave trains that place high pressure over northern North America and the southern Great Plains under northeasterly flow that will tend to be drying (due to moisture advection) and subsiding (due to thermodynamic and vorticity balances). In all cases this local circulation anomaly tends to be within a wave train with a low height anomaly at the North American west coast and a high over eastern Siberia and the east coast of Asia. Further, in all cases the drought onsets are also associated with a west-east dipole of positive-negative precipitation anomalies over the Maritime Continent-equatorial Pacific Ocean. Hence, there is a degree of commonality of the dynamical contexts of the drought onsets. The observed height anomaly in OND 2010 is actually quite similar to the composite height anomaly for La Niñas during September-November shown by Seager et al. (2014). That paper showed that, in the fall season, the La Niña teleconnection is of higher zonal wavenumber than, and quite different to, the more PacificNorth America (PNA)-like pattern during winter and spring and that SST-forced models instead simulate PNA-like La Niña teleconnections in all seasons. Consistent with Seager et al. (2014), in the forecasts, the drought onset in OND 2010 is related to a PNA-like La Niña-driven teleconnection. This biased teleconnection was enough to drive drier than normal conditions in the southern Great Plains across the model ensemble (Fig. 3). The circulation anomalies during the drought onset of OND 2005 also have some characteristics of the observed fall La Niña teleconnection, although the tropical Pacific precipitation anomalies were much weaker than in OND 2010. The forecasts do correctly simulate the pattern of tropical Pacific Ocean precipitation anomalies in OND 2005, but weaker than observed, and entirely fail to forecast the Northern Hemisphere circulation anomalies. The predicted circulation anomaly in AMJ 2012 does have similarities to that observed even though it is much weaker. Since the prediction of this drought onset was a surprise it is considered in more detail below.

The situation for drought terminations is quite different (Fig. 7). Although the observed 200-hPa circulation anomaly places southerly flow over the southern Great Plains, this occurs within hemispheric circulation anomalies that are very different for the three terminations. In addition, there is a considerable difference in the precipitation anomalies: notably the tropical Indo-Pacific anomalies for JFM 1990 and OND 2000 are almost opposite of each other. The forecasts for all these terminations and at all lead times tend to predict reduced precipitation over the equatorial Pacific Ocean but generally very weak circulation anomalies, consistent with the inability to predict the terminations (Fig. 3).

Since predictability on time scales longer than a week or two can come from SSTs, in Figs. 8 and 9 we show the observed and forecast SST anomalies during the DO\&Ts. The cause of the drought onset in OND 2010 is obvious: a strong La Niña event which it has been shown drove a teleconnection pattern that induced dry conditions over Texas and northern Mexico 


\section{Seasonal Drought Onset} Seven Model Precipitation Anomaly Forecast

\section{OND 2005}

OND 2010
AMJ 2012

\section{Lead 2.5 to 4.5 Months}
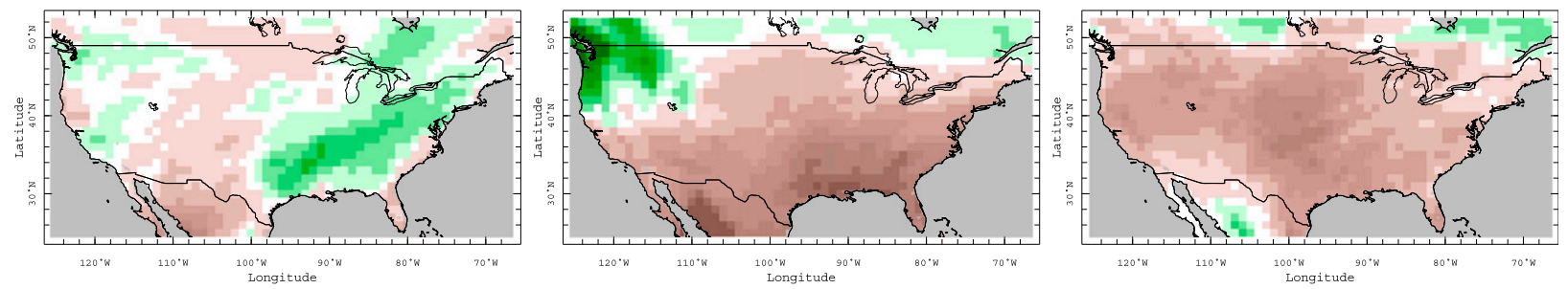

\section{Lead 1.5 to 3.5 Months}
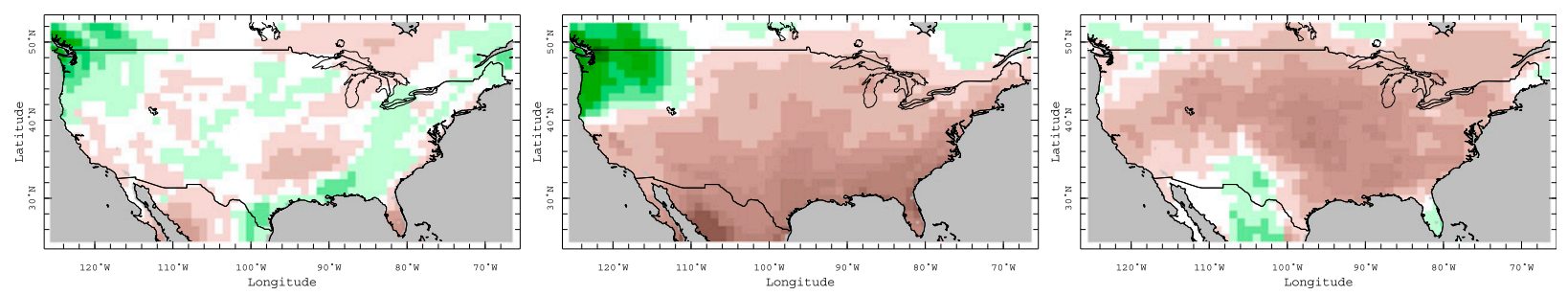

\section{Lead 0.5 to 2.5 Months}
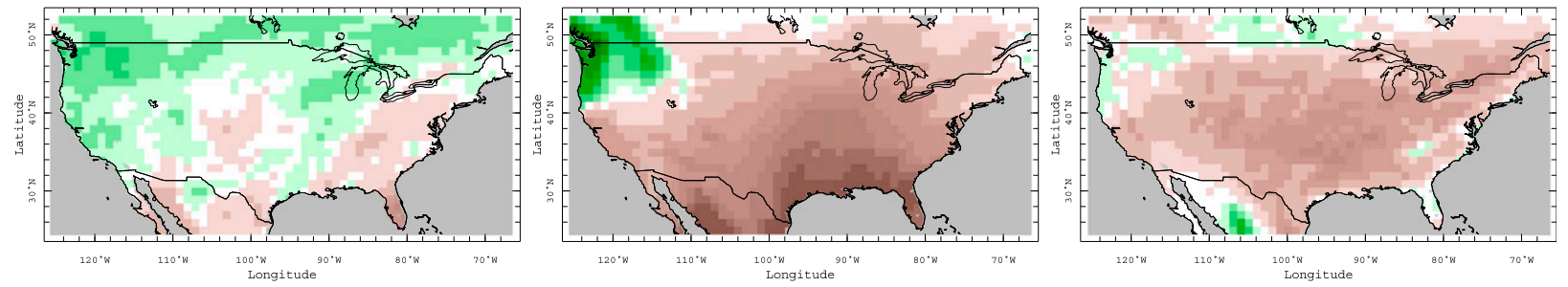

\section{Observed Precipitation Anomaly}
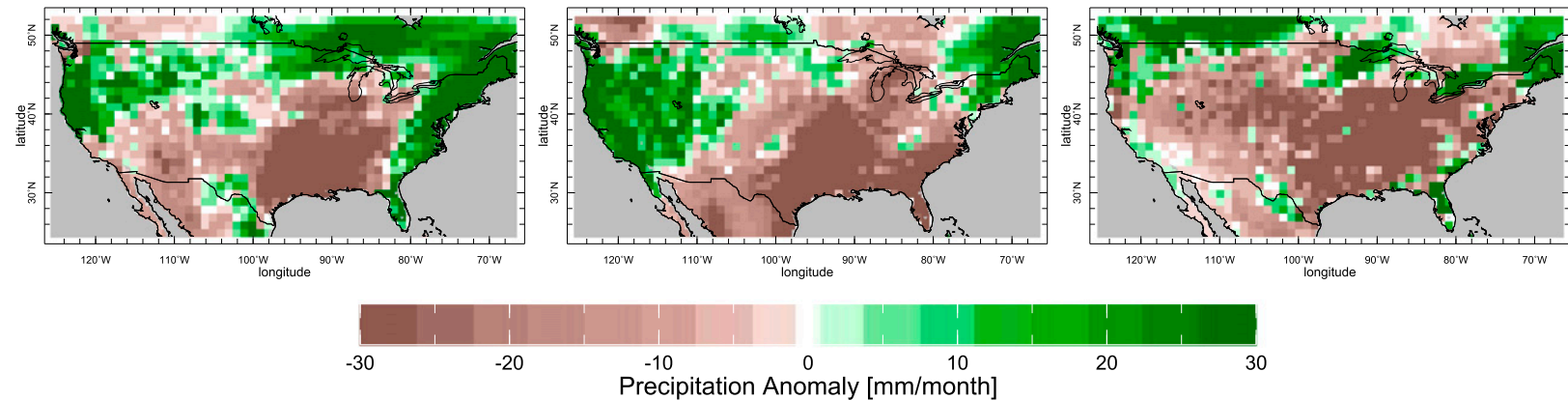

FIG. 4. Predicted NMME multimodel mean precipitation anomalies $\left(\mathrm{mm} \mathrm{month}{ }^{-1}\right)$ at indicated lead times together with, in the bottom row, the observed anomalies for the three seasonal drought onsets.

(Seager et al. 2014). This La Niña was well forecast at all lead times analyzed and, hence, this provided the basis for the robust forecast of drought onset in fall 2010 out to a season in advance. In OND 2005 there were also cold SSTs in the equatorial central and eastern Pacific Ocean, consistent with locally reduced precipitation (Fig. 6), but these were not well forecast even at the shortest lead time and not forecast at all at longer lead times. The poor tropical Pacific SST forecast 


\section{Seasonal Drought Termination Seven Model Precipitation Anomaly Forecast}

JFM 1990

OND 2000

JAS 2006

\section{Lead 2.5 to 4.5 Months}
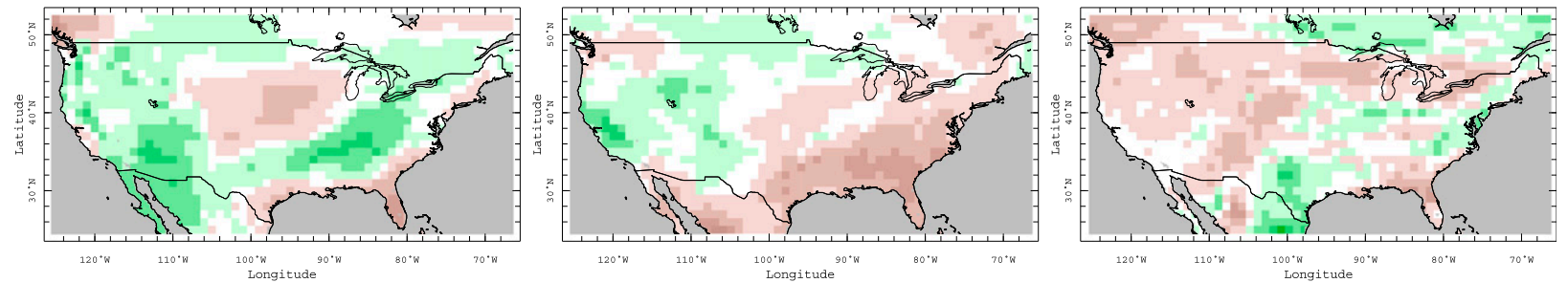

\section{Lead 1.5 to 3.5 Months}
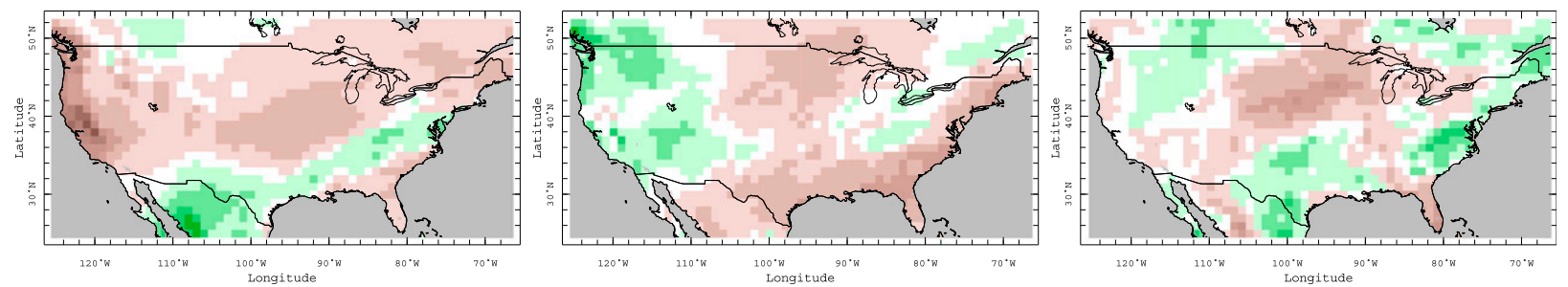

\section{Lead 0.5 to 2.5 Months}
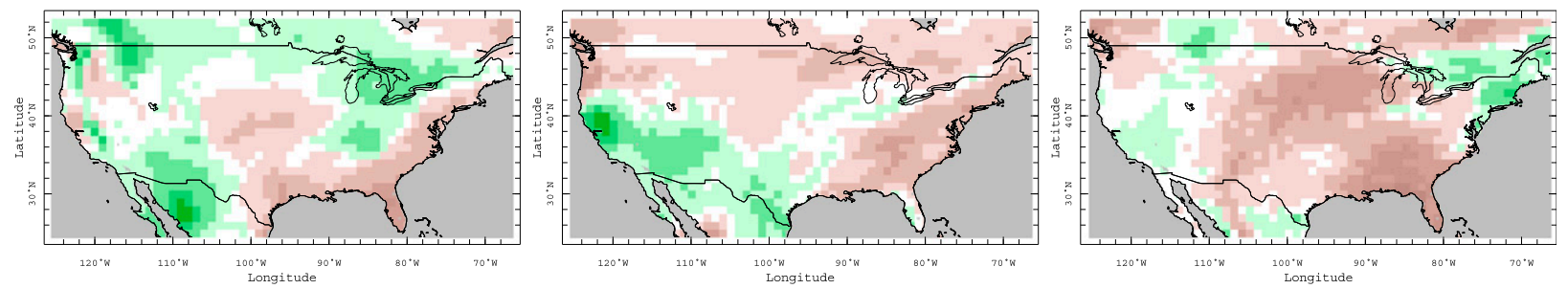

\section{Observed Precipitation Anomaly}
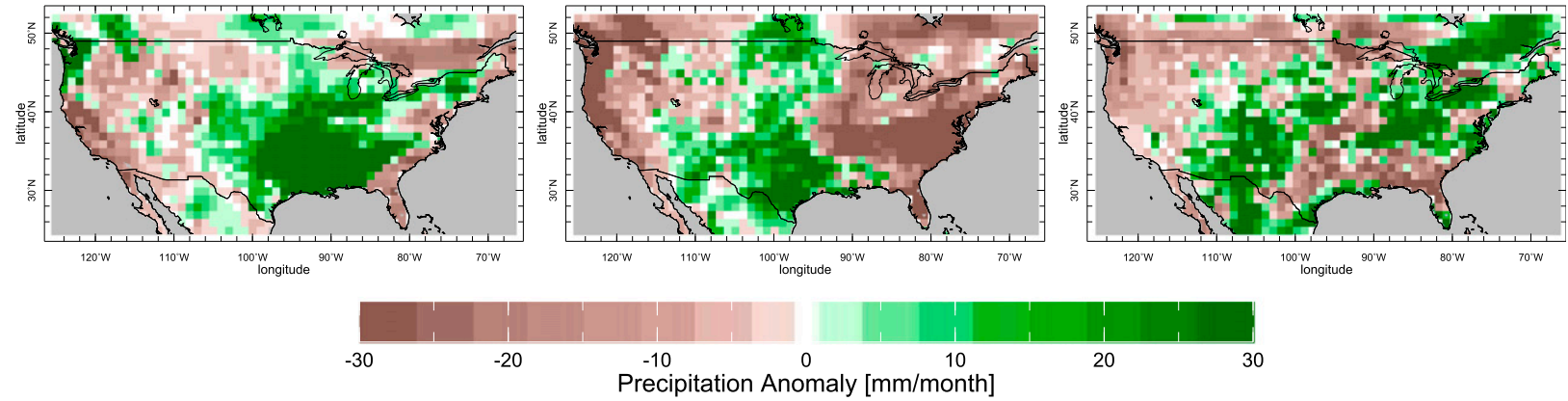

FIG. 5. As in Fig. 4, but for the three seasonal drought terminations.

hindered successful prediction of the drought onset as made clear by the limited success of predictions at the 0.5 -month lead times (Fig. 3). Successful forecast out to the seasonal time scale of the warm tropical North Atlantic did not aid the prediction of drought onset in OND 2005. In AMJ 2012 the Pacific SST anomaly pattern had a horseshoe of cold anomalies that extended from the Aleutians along the coast of the Americas and reached across the tropical Pacific to the western equatorial Pacific and surrounded warm anomalies in the central North Pacific. This pattern of SST 


\section{Seasonal Drought Onset}

7 Model Precipitation (color) and $200 \mathrm{hPa}$ Height (contour) Forecast

OND 2005
OND 2010

AMJ 2012

\section{Lead 2.5 to 4.5 Months}
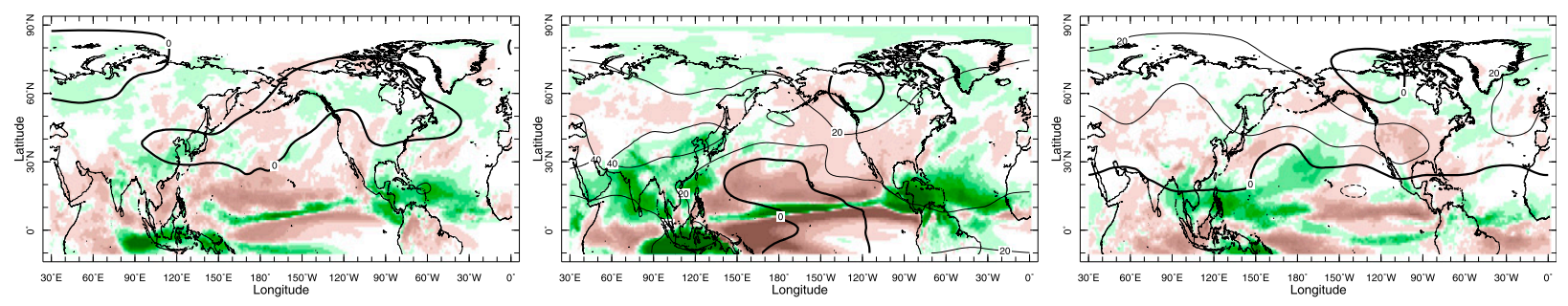

Lead 1.5 to 3.5 Months
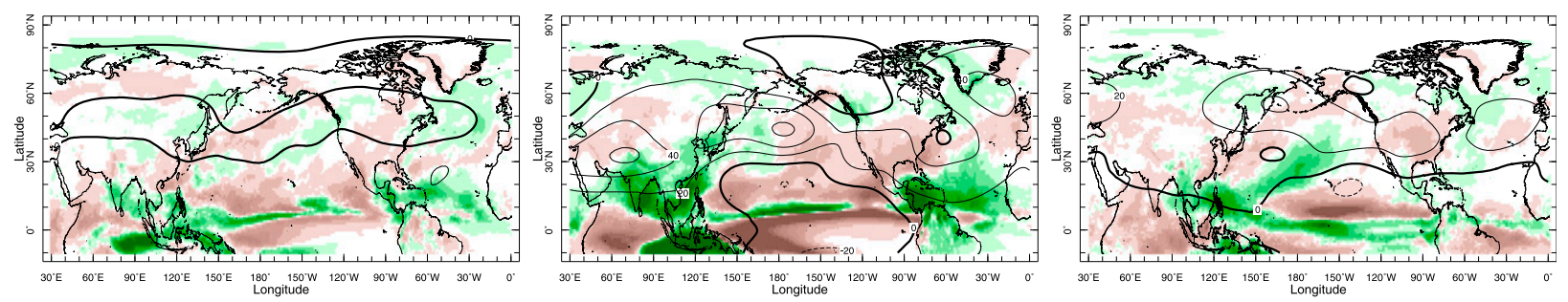

Lead 0.5 to 2.5 Months
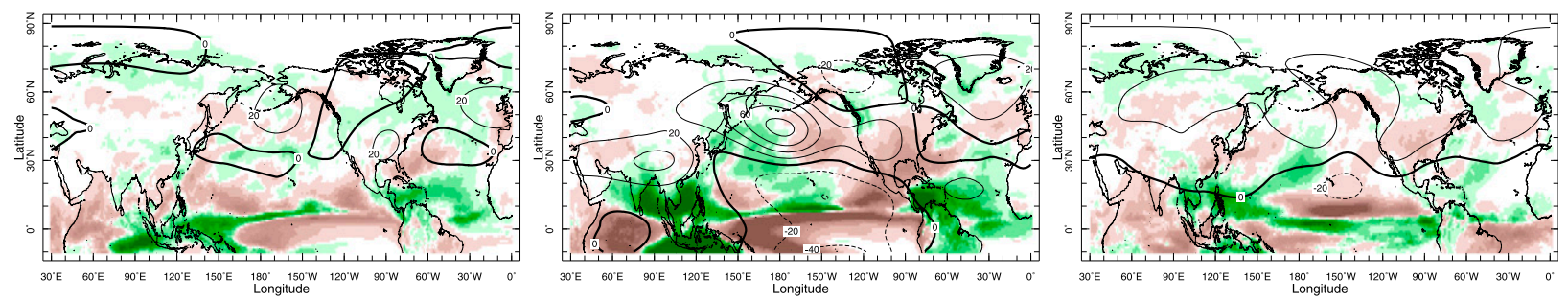

Observed Precipitation (color) and 200 hPa Height (contour)
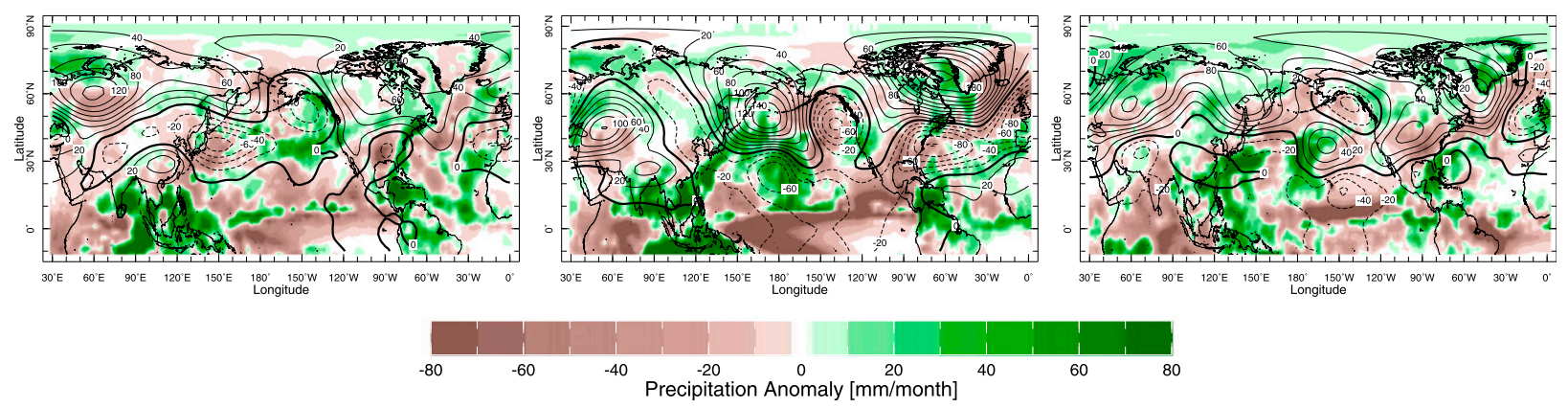

FIG. 6. Large-scale context of predicted and observed seasonal drought onsets. NMME multimodel mean precipitation (colors; $\mathrm{mm}$ month $^{-1}$ ) and 200-hPa height (contours; $\mathrm{m}$ ) anomalies are shown for the indicated forecasts lead times together with, in the bottom row, the observed fields. 


\section{Seasonal Drought Termination}

7 Model Precipitation (color) and $200 \mathrm{hPa}$ Height (contour) Forecast

JFM 1990

OND 2000

JAS 2006

Lead 2.5 to 4.5 Months
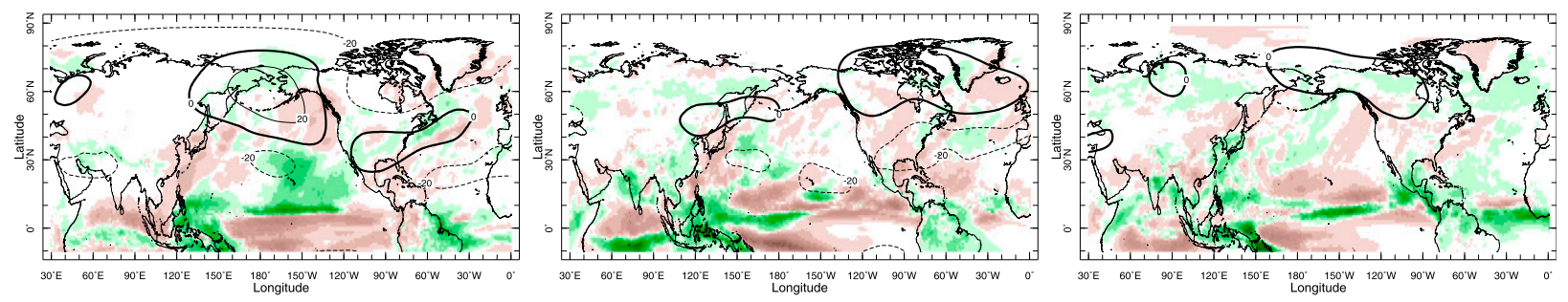

Lead 1.5 to 3.5 Months
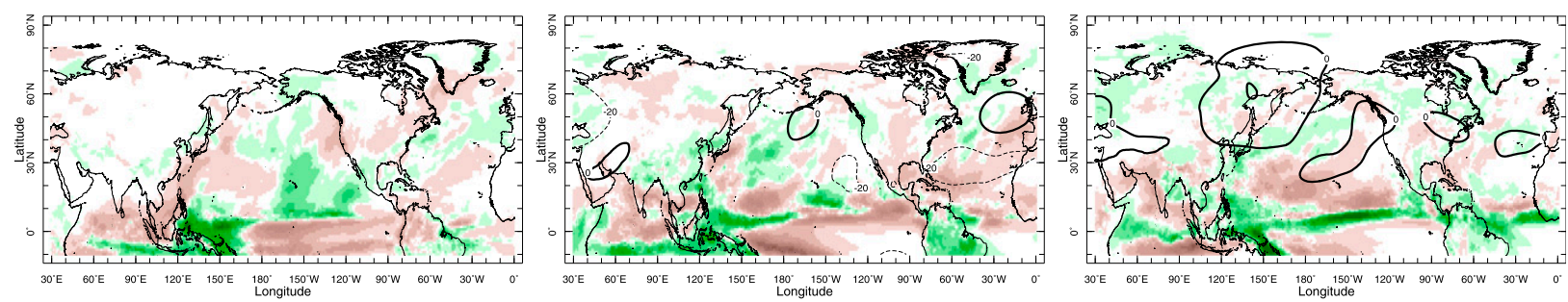

Lead 0.5 to 2.5 Months
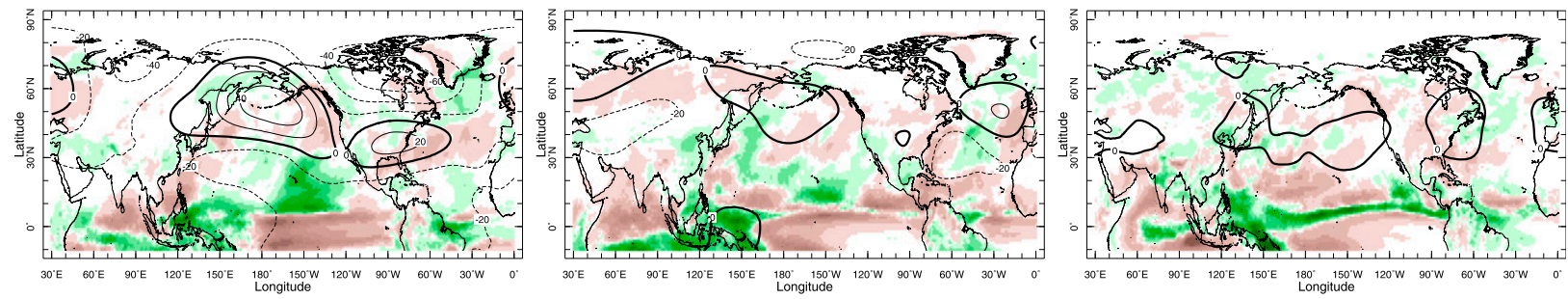

Observed Precipitation (color) and $200 \mathrm{hPa}$ Height (contour)
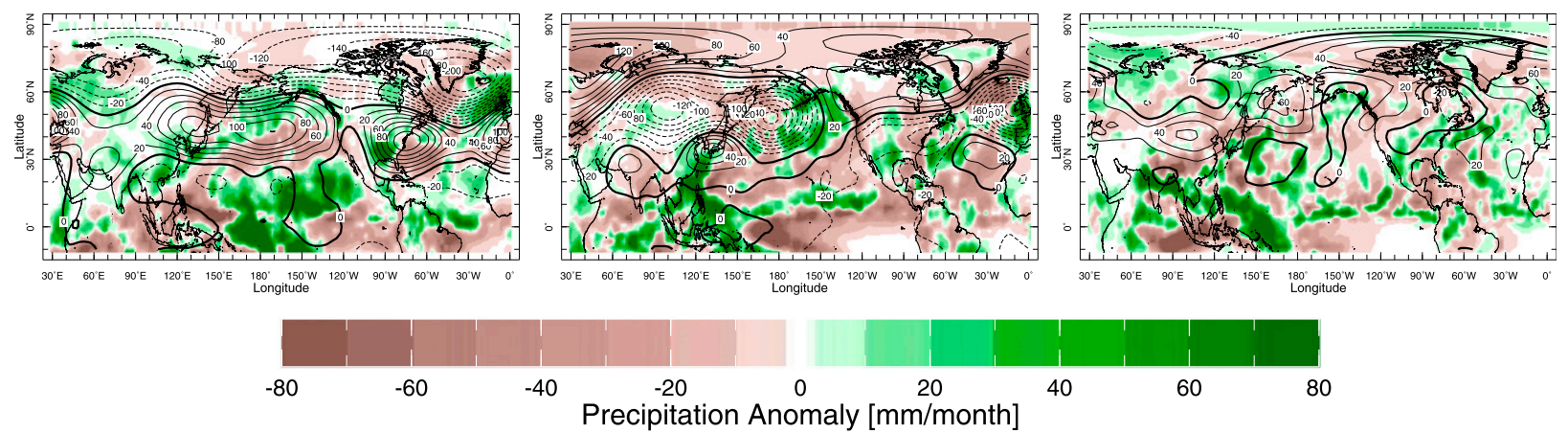

FIG. 7. As in Fig. 6, but for seasonal drought terminations. 


\section{Seasonal Drought Onset}

Seven Model Sea Surface Temperature Anomaly Forecast

OND 2005

OND 2010

AMJ 2012

\section{Lead 2.5 to 4.5 Months}
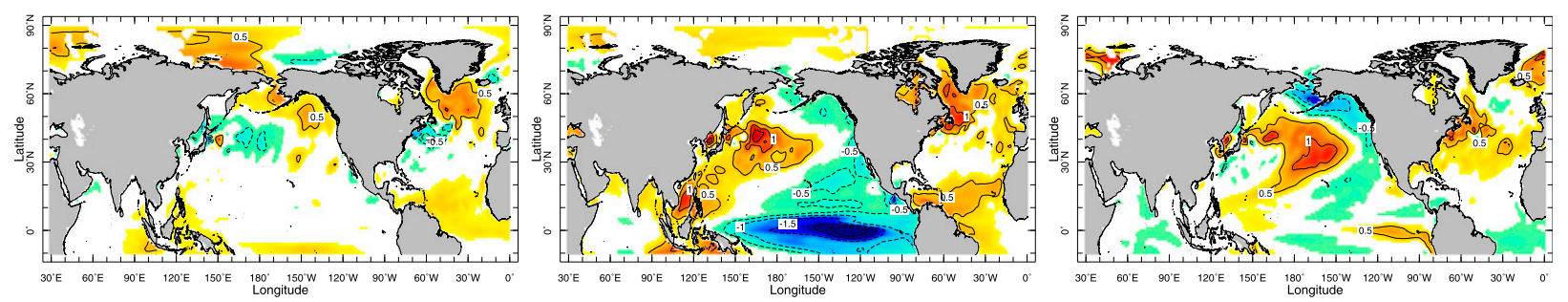

Lead 1.5 to 3.5 Months
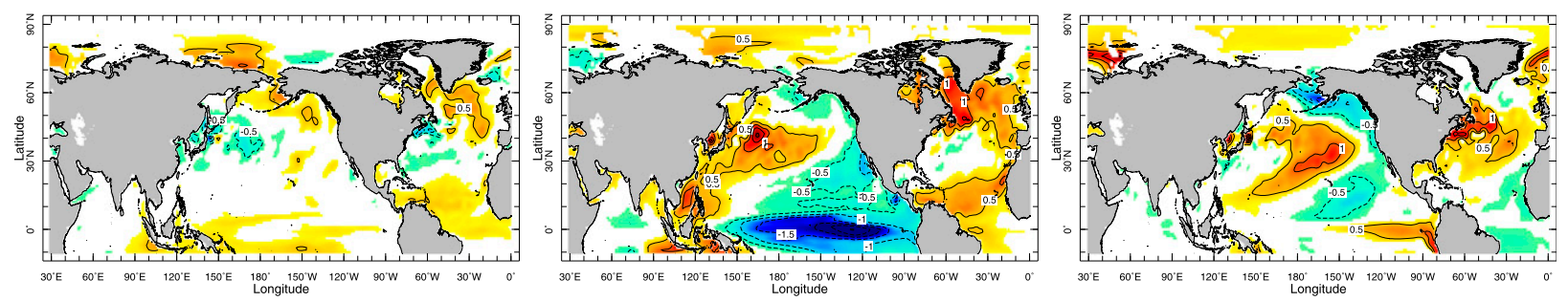

Lead 0.5 to 2.5 Months
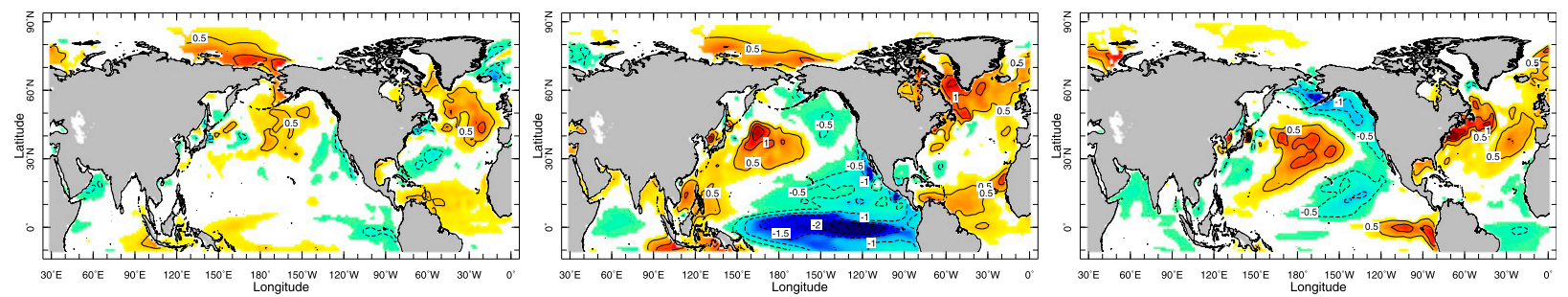

\section{Observed Sea Surface Temperature Anomaly}
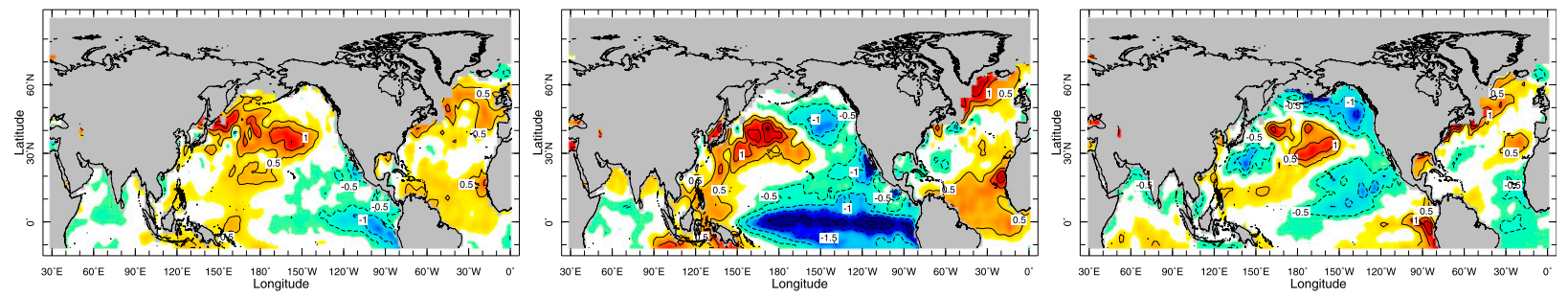

FIG. 8. As in Fig. 6, but the SST forecasts and observations (K) for seasonal drought onsets.

anomalies was well forecast even at the seasonal lead time and translated into a correct prediction of dry conditions in the equatorial Pacific and a teleconnection and dry response over the southern Great Plains, albeit both far weaker than observed (Fig. 6).

For the drought terminations (Fig. 9), JFM 1990 and OND 2000 both had weak cold anomalies in the equatorial
Pacific Ocean while JAS 2006 had weak warm anomalies. Extratropical Pacific SSTs anomalies in JFM 1990 and JAS 2006 were also disorganized and not consistent across terminations. However, there was a very strong warm anomaly directly east of Japan and China in OND 2000. The SST anomalies in JFM 1990 and JAS 2006 were quite well predicted as were the tropical precipitation anomalies that they 


\title{
Seasonal Drought Termination
}

\author{
Seven Model Sea Surface Temperature Anomaly Forecast
}

JFM 1990

OND 2000

JAS 2006

\section{Lead 2.5 to 4.5 Months}
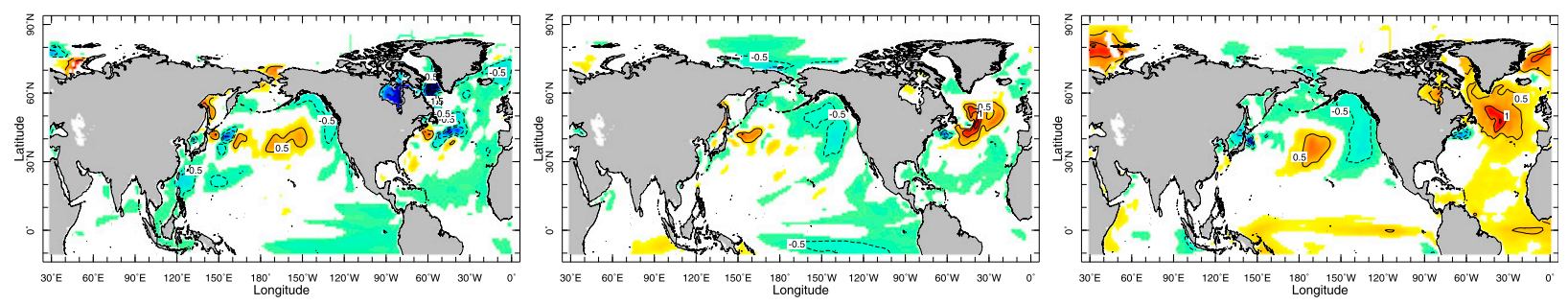

Lead 1.5 to 3.5 Months
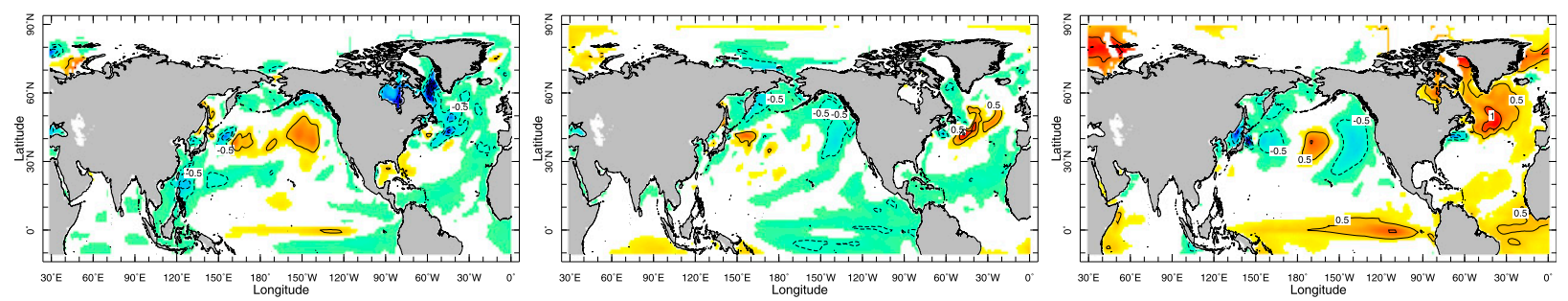

Lead 0.5 to 2.5 Months
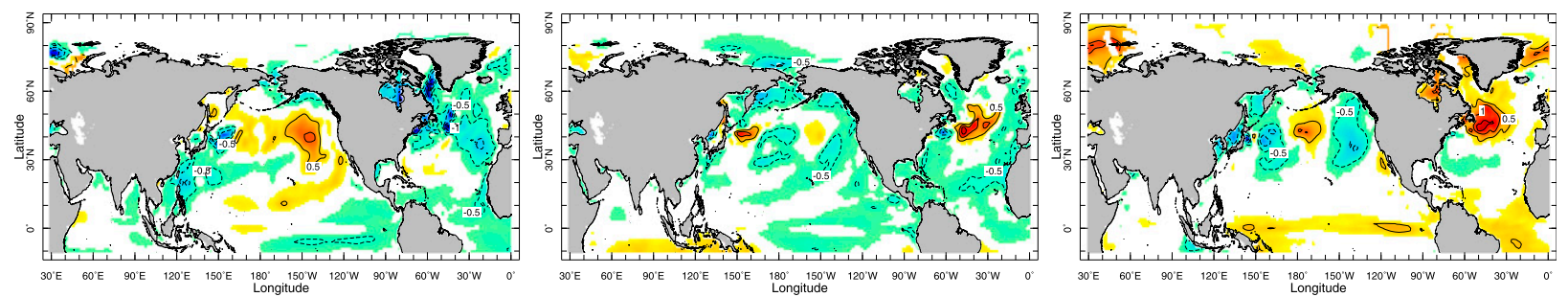

\section{Observed Sea Surface Temperature Anomaly}
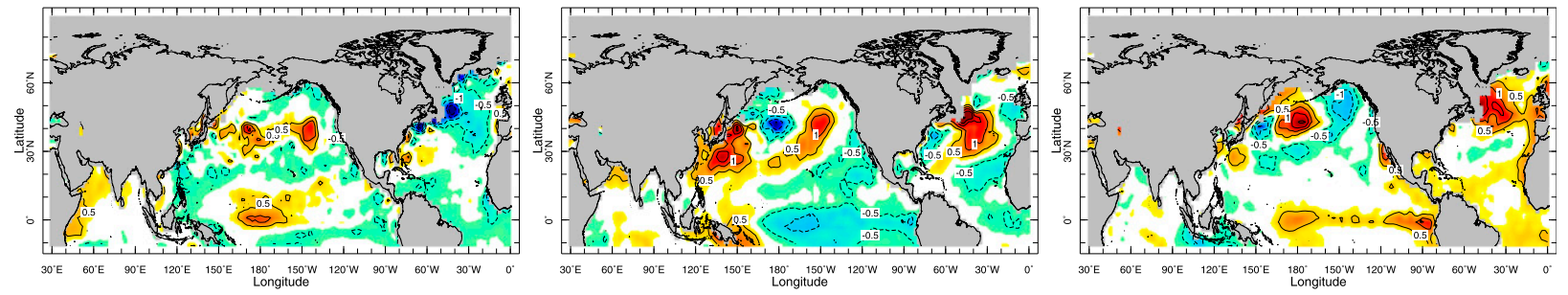

FIG. 9. As in Fig. 8, but for seasonal drought terminations.

drove (Fig. 6) but the La Niña-like conditions and warm waters east of Asia in OND 2000 were poorly predicted. In JFM 1990 the observed SST and tropical Pacific precipitation anomalies appear to translate into a teleconnection that placed strong southerly flow over the southern Great Plains that drove drought termination. This teleconnection was forecast at the shortest seasonal lead time, but the circulation anomaly was weak and the southerly flow placed over the southwest and, hence, the drought termination was not forecasted. The La Niña-like conditions in OND 2000 are opposite to those expected to cause wet conditions over the southern Great Plains but the seasonal mean of 0.5-month forecasts did produce anomalous wet conditions in all seven model ensemble means (Fig. 3). Predictions of drought onset in 


\section{AMJ 2012 Drought Onset}

7 Model Precipitation (color) and 200 hPa Height (contour) Forecast

Apr 2012
May 2012

Lead 0.5 to 2.5 Months
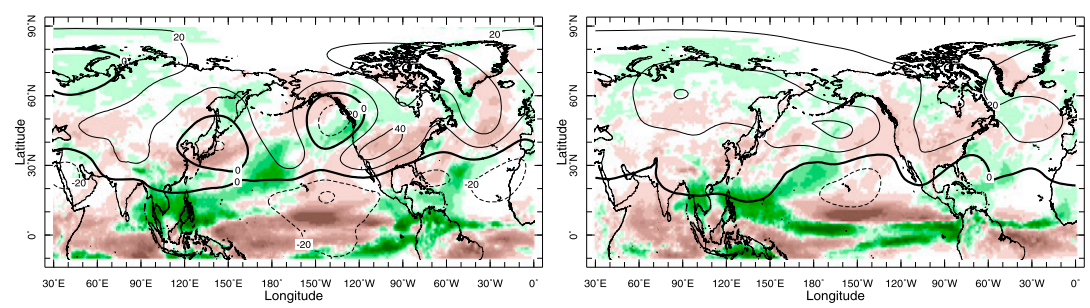

Jun 2012

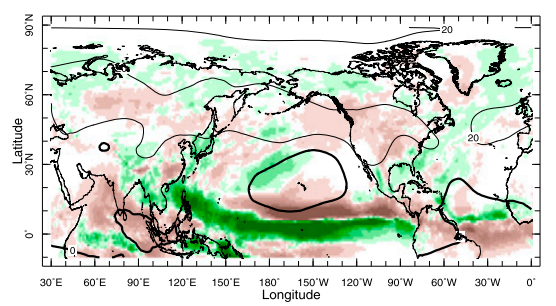

\section{Lead 0.5 Months}
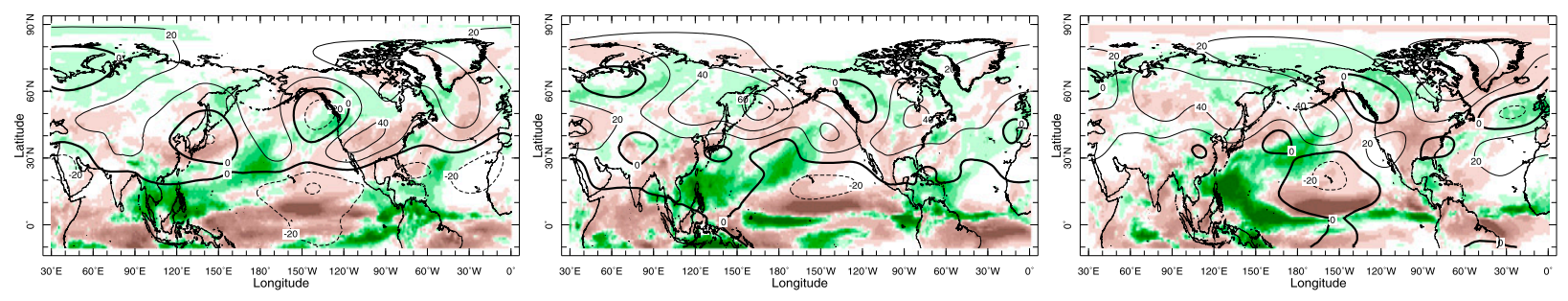

\section{Observed Precipitation (color) and $200 \mathrm{hPa}$ Height (contour)}
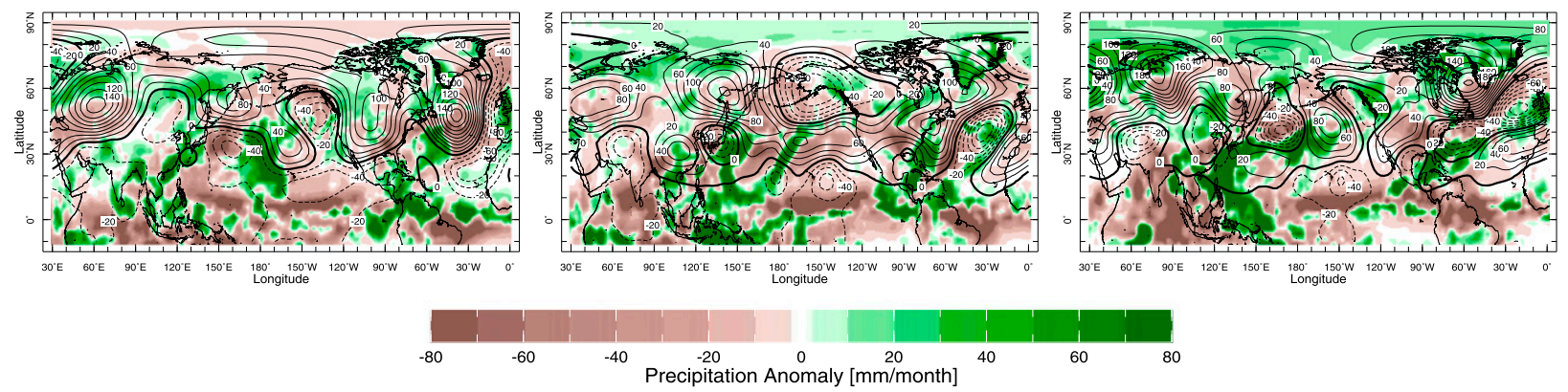

FIG. 10. Observed and forecast precipitation $\left(\mathrm{mm} \mathrm{month}^{-1}\right)$ and 200-hPa height anomalies $(\mathrm{m})$ during the three months of the AMJ 2012 drought onset. Columns are for (left) April, (center) May, and (right) June of 2012. (top) The forecast of the month shown from 1 Apr 2012, that is, at 0.5-, 1.5-, and 2.5-month lead times. (middle) The 0.5-month lead time forecasts. (bottom) The observed values.

AMJ 2012 and of drought termination in OND 2000 were not expected by SNT and are considered in more detail next.

\section{d. The drought onset in AMJ 2012 and drought termination in OND 2000}

\section{1) MONTHLY ANALYSIS FOR DROUGHT ONSET IN} AMJ 2012

The authors of SNT did not think [consistent with Hoerling et al. (2014)] that AMJ 2012 was a case of SST-forced drought onset and hence even the limited success of its prediction here was a surprise. Hoerling et al. (2014) and Basara et al. (2019) both point out that this drought onset was not preceded by abnormally low soil moisture anomalies. The seasonal mean height anomalies, however, are also weak in the forecasts. To take a closer look at this case, in which the southern Plains were part of a near pan-continental drought (Cook et al. 2014; Baek et al. 2019), we examine the three months within AMJ 2012 separately (Fig. 10). In the observations each month had northerly or easterly flow over the southern Great Plains and was drier than normal, each contributing to the drought onset. In the forecasts each month was also drier than normal but none to the extent observed. In the 0.5 -month lead forecasts for all three months there is a weak wave train, originating in the tropical Pacific, that places flow with a northerly (drying) component over the southern Great Plains. This weak, tropically forced wave train explains the weak tendency to drier than normal conditions in the forecasts (Fig. 3). 

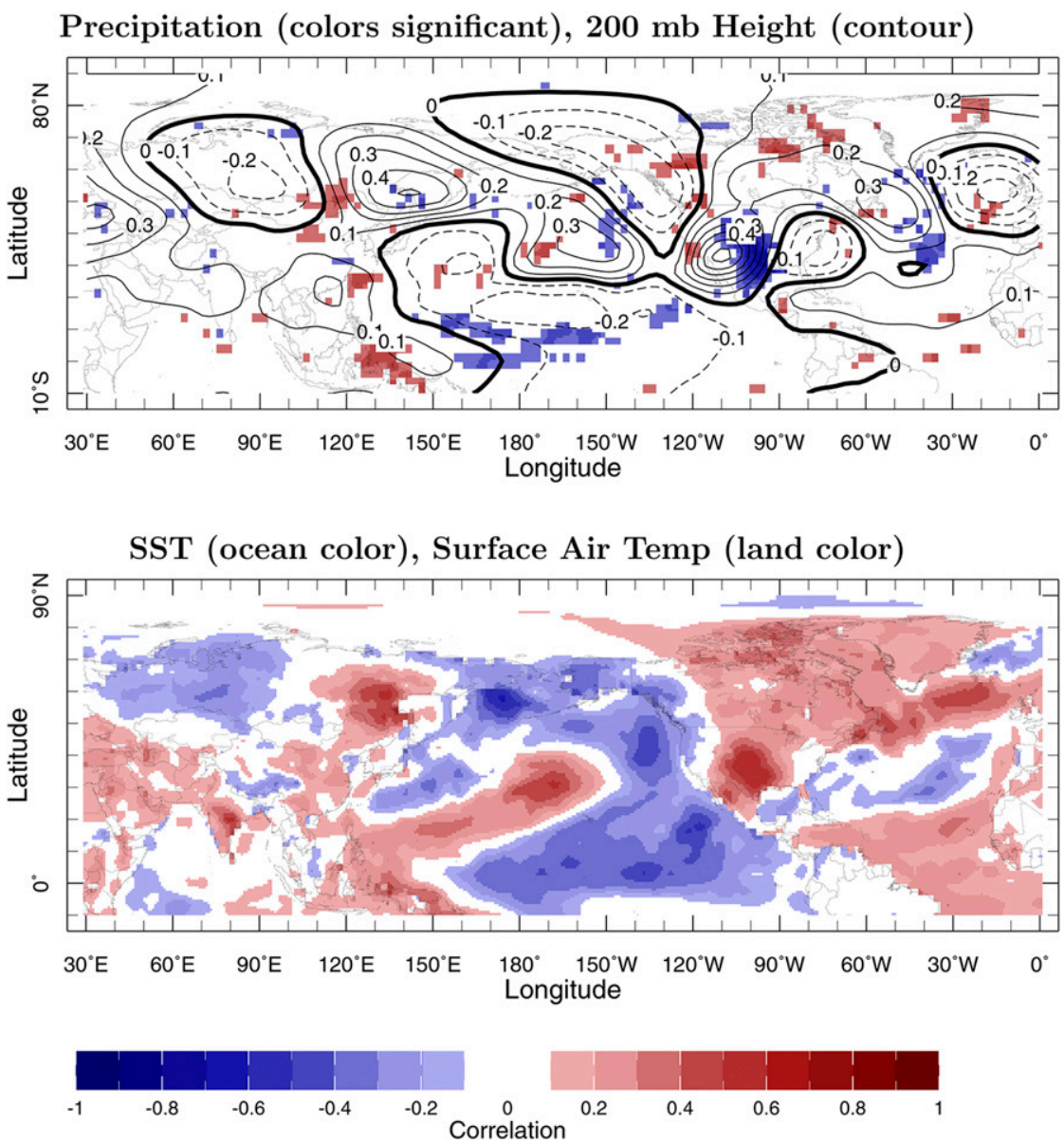

FIG. 11. The correlation within observations with AMJ southern Plains precipitation of (top) precipitation (colors, where significant at the $5 \%$ level) and $200-\mathrm{hPa}$ heights (contours) and (bottom) SSTs (ocean) and surface air temperature (land).

The observations have a hint of this tropically forced wave train (especially in April and June) but it appears within what is most likely much stronger wave trains arising from internal atmosphere dynamics that augmented the dry conditions over the southern Great Plains. The strong role for internal atmosphere variability in the AMJ 2012 drought onset is supported by the circulation anomalies being quite different month to month even as the SST anomalies evolved more slowly. The forecasts for May and June 2012 from 1 April (Fig. 10, top row) have muted circulation anomalies and dry conditions lacking the details of the observed anomalies or those of the 0.5 -month lead time forecasts testifying to the month-to-month variability that occurred during this drought onset.

2) THE GENERAL RELATION BETWEEN SPRING PRECIPITATION ANOMALIES IN THE SOUTHERN GREAT PLAINS AND HEMISPHERIC-SCALE CIRCULATION ANOMALIES

The NMME suggests that the AMJ 2012 precipitation anomalies in the southern Great Plains that drove a drought onset might have been to some extent predictable in terms of SST. It is worth determining if anomalies in this particular year and season were unusual or typical of spring anomalies. Figure 11, therefore, shows the correlation in observations between AMJ precipitation anomalies in the southern Great Plains and precipitation and $200-\mathrm{hPa}$ circulation anomalies across the Northern Hemisphere. The spatial correlation coefficient in the $10^{\circ} \mathrm{S}-90^{\circ} \mathrm{N}$ domain between this height pattern and that observed in April, May, and June 2012 is 0.33, 0.37, and 0.31 , respectively, and with AMJ 2012 is 0.43 . The strength of these spatial correlation coefficients suggests that the connections between hemispheric scale circulation anomalies and precipitation in the southern Great Plains in spring 2012 was to some extent typical of conditions that drive spring precipitation anomalies in the region. These are La Niña SST conditions in the tropical Pacific and a wave train that extends from the western tropical North Pacific across the Pacific to North America. Interestingly this wave train has a higher zonal wavenumber than the typical La Niña teleconnection pattern (identified via regression on SST) as in Seager et al. (2014) and deserves more dynamical investigation in the future. 


\title{
OND 2000 Drought Termination
}

\author{
Precipitation (color) and $200 \mathrm{hPa}$ Height (contour)
}

Oct 2000

Nov 2000

Dec 2000

7 Model Forecast Lead 0.5 Months
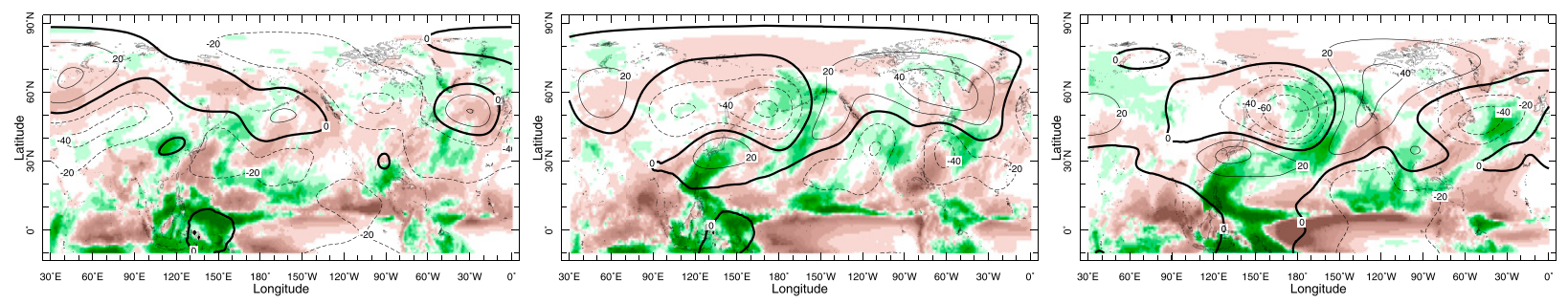

Observed
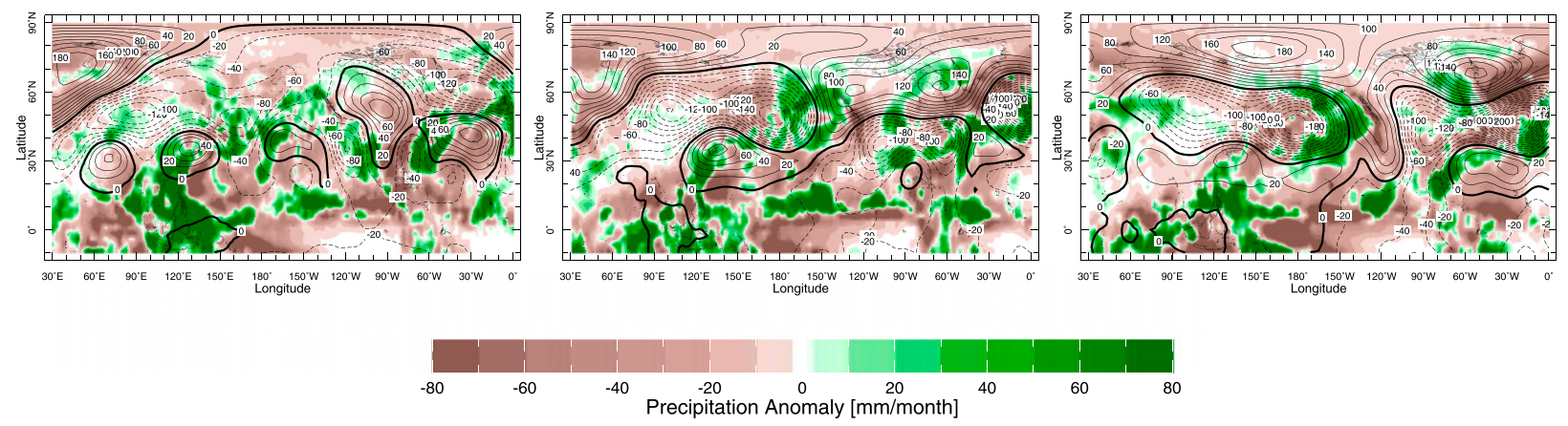

FIG. 12. (top) Forecast at 0.5 -month lead time and (bottom) observed precipitation ( $\mathrm{mm} \mathrm{month}^{-1}$ ) and 200-hPa height anomalies (m) during the three months of the OND 2000 drought termination. Columns are for (left) October, (center) November, and (right) December of 2000.

\section{3) Monthly ANALYSIS FOR DROUGHT TERMinAtion IN OND 2000}

The case of drought termination in OND 2000 is interesting in that the seasonal forecasts failed to predict this event but the seasonal mean of the 1-month forecasts was modestly successful (Fig. 3). Relevantly, we noted that the models failed to forecast the warm SST immediately east of subtropical Asia. In Fig. 12 we show the observed and 0.5-month lead time forecast 200-hPa height and precipitation anomalies. The observed drought termination appears to have been caused by wet anomalies over the southern Great Plains in November 2000. These occurred with the southerly flow over the region within a quadrupole circulation anomaly with low heights over southern North America, high heights over northern North America, low heights over northeast Asia and the northwest Pacific and high heights directly east of subtropical Asia. This circulation anomaly to some extent persisted into December 2000 even though that month was not wet over the southern Great Plains. These circulation anomalies were simulated in the multimodel mean which also, due to ensemble averaging, makes clear the wave train originating from widespread positive precipitation anomalies east of subtropical Asia. The persistence of the circulation in observations and ability to reproduce in the forecasts are strongly suggestive of a role for SST forcing.

\section{Discussion and conclusions}

We have investigated how well drought onsets and termination in the southern Great Plains are predicted on the seasonal time scale in the North American Multimodel Ensemble. The onsets and terminations had been previously identified based on soil moisture transitions in land data assimilation systems for the 1979 to recent period. The earlier work demonstrated that all the onsets and terminations were driven by precipitation anomalies. Hence, given the absence of soil moisture data for some prediction models and lack of uniformity of data across other models, here we examine the prediction of the driving precipitation anomalies. Conclusions are as follows.

- Drought onset can be favored by La Niña conditions in the tropical Pacific Ocean that drive a wave train that places northerly flow above the southern Great Plains. This provides a source of predictability for drought onsets, but this will be limited by SST prediction skill and also, in the fall season, biases in the height teleconnection pattern.

- Ocean forcing alone may on occasions be sufficient to induce drought onset as in OND 2010 when strong La Niña conditions 
prevailed. However, more generally, onset will require some constructive influence from internal atmosphere variability as in AMJ 2012.

- In contrast to onsets, none of the three drought terminations were predicted even at the shortest seasonal lead times. This is consistent with the observation that, while there was an association between La Niñas and drought onset, there was no association between El Niños and drought terminations. However, termination was predicted at the 0.5-month lead time in fall 2010 and seems to be related to warm SST anomalies directly east of subtropical Asia which were not predicted even a season in advance.

- Modest skill in predicting the drought onset of spring 2012 was not expected based on the weak tropical Pacific SST anomalies at this time. However, investigation of the individual months of AMJ 2012, and the general relation between AMJ precipitation over the southern Great Plains and circulation and SST, does suggest that this onset was partly forced by SST anomalies in the tropical Pacific Ocean.

The message from this work is varied. In some cases, it may be possible to exploit a successful prediction of La Niña conditions to successfully predict a drought onset over the southern Great Plains. However, onsets can also occur in the absence of tropical SST influence. Also, models might fail to predict La Niña-like SST anomalies. OND 2005 seems to be a case of the latter situations: a weak La Niña SST anomaly was not predicted and a drought onset occurred with a circulation anomaly that did not anyway seem connected to the SST anomaly. In contrast to onsets, the drought terminations were not predictable on the seasonal time scale. However, the apparent skill in predicting drought termination in OND 2010 at the 0.5 -month lead time suggests predictability might be advanced by improved SST prediction. In particular, it appears there is a connection between SST and precipitation anomalies directly east of Asia and waves that propagate east from there to influence North America. The East Asia-North America teleconnection has previously been studied in winter (Yang et al. 2002) and summer (Zhu and Li 2016; Zhao et al. 2018; Lopez et al. 2019) but further examination of this teleconnection in fall and in this context would be worthwhile.

It should be noted that we also cannot rule out based on these forecast model analyses a role for soil moisture anomalies in influencing drought onset and termination. Because of the definition of drought onsets and terminations used here and the fact that they were driven by precipitation anomalies as shown in SNT, there has to be an association between normal to wet soil moisture anomalies and subsequent negative precipitation anomalies for onsets and dry soil moisture anomalies and subsequent positive precipitation anomalies for terminations. To work out whether these soil moisture anomalies mattered for the subsequent precipitation would require controlled experiments in which the soil moisture initial conditions are adjusted. However, in the NMME ensemble some models initialize soil moisture and some do not, and not all the groups report soil moisture. Hence this matter requires more investigation in the future that compares sources of predictability arising from the atmosphere, ocean and land.
Further, attention is needed to assess how land surface and vegetation feedbacks influence precipitation and evapotranspiration during the period of drought onset and termination (Basara et al. 2019) and whether the forecast models correctly simulate these if included, or what the impacts are if they are neglected (e.g., vegetation processes).

Another important caveat for this work is that we have limited our attention to a short period covered both by the land data assimilation systems used to identify the events and the NMME hindcasts and forecasts. While the hindcasts will not be extended back in time, observed and SST-forced modeled drought onsets and terminations could be examined exploiting model-calibrated soil moisture reconstructions as in Williams et al. (2017). This would allow improved characterization of onsets and termination by extending the number of events. Then SST-forced models would allow an assessment of their predictability in the presence of perfect SST forecasts. Such work might be useful to answer the critical questions of whether drought onsets truly are more predictable than terminations and, if so, why? The current work focuses on the southern Great Plains which had previously been identified as a geographic center of continental-scale patterns of soil moisture change over time. According to the model-based assessment of Seager and Hoerling (2014) this is also the location of the highest ratio across North America of SST-forced precipitation variance to the total variance. Hence, while it needs to be examined more in detail, we anticipate that drought onsets and terminations in other regions of North America will be even less predictable than in the southern Great Plains. To some extent, prediction skill could improve as models and SST forecasts improve but the strong role of internal atmospheric variability will limit forecast skill on the seasonal time scale. Hence, the best advice is that those affected by drought should always have contingency plans for onset and termination in place and not wait for seasonal forecasts before being prepared.

Acknowledgments. This work was supported by NOAA MAPP program Award NA17OAR4310126 and NSF Award OCE-1657209. We thank three anonymous reviewers for constructive criticism. This is LDEO Contribution Number 8442.

\section{REFERENCES}

Baek, S., J. Smerdon, S. Coats, R. Seager, A. Williams, and B. Cook, 2019: Pacific Ocean forcing and atmospheric variability are the dominant causes of spatially widespread droughts in the contiguous United States. J. Geophys. Res. Atmos., 124, 2507-2524, https://doi.org/10.1029/2018JD029219.

Basara, J. B., and J. I. Christian, 2018: Seasonal and interannual variability of land-atmosphere coupling across the Southern Great Plains of North America using the North American regional reanalysis. Int. J. Climatol., 38, 964-978, https:// doi.org/10.1002/joc.5223.

—, J. Christian, R. Wakefield, J. Otkin, E. Hunt, and D. Brown, 2019: The evolution, propagation, and spread of flash droughts in the Central United States during 2012. Environ. Res. Lett., 14, 084025, https://doi.org/10.1088/1748-9326/ab2cc0. 
Cook, B., J. E. Smerdon, R. Seager, and E. R. Cook, 2014: Pancontinental droughts in North America over the last millennium. J. Climate, 27, 383-397, https://doi.org/10.1175/JCLI-D-13-00100.1.

Daly, C., W. P. Gibson, G. H. Taylor, G. L. Johnson, and P. Pasteris, 2000: High-quality spatial climate data sets for the United States and beyond. Trans. ASAE, 43, 1957-1962, https://doi.org/10.13031/2013.3101.

Ford, T. W., S. M. Quiring, and O. W. Frauenfeld, 2017: Multi-decadal variability of soil moisture-temperature coupling over the contiguous United States modulated by Pacific and Atlantic sea surface temperatures. Int. J. Climatol., 37, 1400-1415, https:// doi.org/10.1002/joc.4785.

Herweijer, C., R. Seager, and E. R. Cook, 2006: North American droughts of the mid to late nineteenth century: History, simulation and implications for Medieval drought. Holocene, 16, 159-171, https://doi.org/10.1191/0959683606hl917rp.

Hoerling, M. P., J. Eischeid, A. Kumar, R. Leung, A. Mariotti, K. Mo, S. Schubert, and R. Seager, 2014: Causes and predictability of the 2012 Great Plains drought. Bull. Amer. Meteor. Soc., 95, 269-282, https://doi.org/10.1175/BAMS-D-13-00055.1.

Huffman, G. J., and Coauthors, 1997: The Global Precipitation Climatology Project (GPCP) combined precipitation dataset. Bull. Amer. Meteor. Soc., 78, 5-20, https://doi.org/10.1175/ 1520-0477(1997)078<0005:TGPCPG > 2.0.CO;2.

Karl, T., F. Quinlan, and D. Ezell, 1987: Drought termination and amelioration: Its climatological probability. J. Climate Appl. Meteor., 26, 1198-1209, https://doi.org/10.1175/1520-0450(1987) 026<1198:DTAAIC $>2.0$. CO;2.

Kirtman, B., and Coauthors, 2014: The North American multimodel ensemble: Phase-1 seasonal-to-interannual prediction; phase-2 toward developing intraseasonal prediction. Bull. Amer. Meteor. Soc., 95, 585-601, https://doi.org/10.1175/BAMS-D-12-00050.1.

Kistler, R., and Coauthors, 2001: The NCEP-NCAR 50-Year Reanalysis: Monthly means CD-ROM and documentation. Bull. Amer. Meteor. Soc., 82, 247-267, https://doi.org/10.1175/ 1520-0477(2001)082<0247:TNNYRM >2.3.CO;2.

Koster, R., and Coauthors, 2004: Regions of strong coupling between soil moisture and precipitation. Science, 305, 1138-1140, https://doi.org/10.1126/science.1100217.

Kumar, A., and M. P. Hoerling, 1998: Annual cycle of Pacific-North American seasonal predictability associated with different phases of ENSO. J. Climate, 11, 3295-3308, https://doi.org/ 10.1175/1520-0442(1998)011<3295:ACOPNA>2.0.CO;2.

Kushnir, Y., R. Seager, M. Ting, N. Naik, and J. Nakamura, 2010: Mechanisms of tropical Atlantic SST influence on North American hydroclimate variability. J. Climate, 23, 5610-5628, https://doi.org/10.1175/2010JCLI3172.1.

Lopez, H., S. Lee, S. Dong, G. Goni, B. Kirtman, R. Atlas, and A. Kumar, 2019: East Asian monsoon as a modulator of U.S. Great Plains heatwaves. J. Geophys. Res. Atmos., 124, 6342-6358, https://doi.org/10.1029/2018JD030151.

Maxwell, J., J. T. Ortegren, P. A. Knapp, and P. T. Soule, 2013: Tropical cyclones and drought amelioration in the Gulf and southeastern coastal United States. J. Climate, 26, 8440-8452, https://doi.org/10.1175/JCLI-D-12-00824.1.

_ , P. A. Knapp, J. T. Ortegren, D. L. Ficklin, and P. T. Soule, 2017: Changes in the mechanisms causing rapid drought cessation in the southeastern United States. Geophys. Res. Lett., 44, 12 476-12 483, https://doi.org/10.1002/2017GL076261.

Miralles, D., P. Gentine, S. I. Seneviratne, and A. J. Teuling, 2019: Land-atmosphere feedbacks during droughts and heatwaves: State of the science and current challenges. Ann. N. Y. Acad. Sci., 1436, 19-35, https://doi.org/10.1111/nyas.13912.
Mo, K. C., 2011: Drought onset and recovery over the United States. J. Geophys. Res., 116, D20106, https://doi.org/10.1029/ 2011JD016168.

— over the United States. J. Hydrometeor., 17, 1169-1184, https://doi.org/10.1175/JHM-D-15-0158.1.

Nigam, S., B. Guan, and A. Ruiz-Barradas, 2011: Key role of the Atlantic Multidecadal Oscillation in 20th century drought and wet periods over the Great Plains. Geophys. Res. Lett., 38, L16713, https://doi.org/10.1029/2011GL048650.

NOAA/NCEI, 2020a: Calculating the cost of weather and climate disasters. Accessed 26 June 2020, https://www.ncei.noaa.gov/ news/calculating-cost-weather-and-climate-disasters.

_- 2020b: Drought: Monitoring economic, environmental, and social impacts. Accessed 26 June 2020, https://www.ncdc.noaa.gov/ news/drought-monitoring-economic-environmental-and-socialimpacts.

Otkin, J. A., and Coauthors, 2016: Assessing the evolution of soil moisture and vegetation conditions during the 2012 United States flash drought. Agric. For. Meteor., 218-219, 230-242, https://doi.org/10.1016/j.agrformet.2015.12.065.

Pu, B., R. Fu, R. Dickinson, and D. Nelun Fernando, 2016: Why do summer droughts in the southern Great Plains occur in some La Niña years but not others? J. Geophys. Res. Atmos., 121, 1120-1137, https://doi.org/10.1002/2015JD023508.

Schubert, S. D., M. J. Suarez, P. J. Pegion, R. D. Koster, and J. T. Bacmeister, 2004a: Causes of long-term drought in the United States Great Plains. J. Climate, 17, 485-503, https://doi.org/ 10.1175/1520-0442(2004)017<0485:COLDIT>2.0.CO;2.

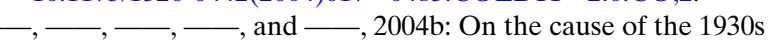
Dust Bowl. Science, 303, 1855-1859, https://doi.org/10.1126/ science. 1095048 .

—, and Coauthors, 2009: A U.S. CLIVAR project to assess and compare the responses of global climate models to droughtrelated SST forcing patterns: Overview and results. J. Climate, 22, 5251-5272, https://doi.org/10.1175/2009JCLI3060.1.

Seager, R., and M. P. Hoerling, 2014: Atmosphere and ocean origins of North American drought. J. Climate, 27, 4581-4606, https://doi.org/10.1175/JCLI-D-13-00329.1.

—, Y. Kushnir, C. Herweijer, N. Naik, and J. Velez, 2005: Modeling of tropical forcing of persistent droughts and pluvials over western North America: 1856-2000. J. Climate, 18, 4065-4091, https://doi.org/10.1175/JCLI3522.1.

—, L. Goddard, J. Nakamura, N. Naik, and D. Lee, 2014: Dynamical causes of the 2010/11 Texas-northern Mexico drought. J. Hydrometeor., 15, 39-68, https://doi.org/10.1175/ JHM-D-13-024.1.

___, J. Nakamura, and M. Ting, 2019: Mechanisms of seasonal soil moisture drought and onset in the southern Great Plains. J. Hydrometeor., 20, 751-771, https://doi.org/10.1175/ JHM-D-18-0191.1.

Sun, Y., R. Fu, R. Dickinson, J. Joiner, C. Frankenberg, L. Gu, Y. Xia, and N. Fernando, 2015: Drought onset mechanisms revealed by satellite solar-induced chlorophyll fluorescence: Insights from two contrasting extreme events. J. Geophys. Res. Biogeosci., 120, 2427-2440, https://doi.org/10.1002/2015JG003150.

Tuttle, S., and G. Salvucci, 2016: Empirical evidence of contrasting soil moisture-precipitation feedbacks across the United States. Science, 352, 825-828, https://doi.org/10.1126/science.aaa7185.

Vins, H., J. Bell, S. Saha, and J. J. Hess, 2015: The mental health outcomes of drought: A systematic review and causal process diagram. Int. J. Environ. Res. Public Health, 12, 13 251-13 275, https://doi.org/10.3390/ijerph121013251. 
Welty, J., and X. Zeng, 2018: Does soil moisture affect warm season precipitation over the southern Great Plains? Geophys. Res. Lett., 45, 7866-7873, https://doi.org/10.1029/2018GL078598.

Williams, A. P., B. Cook, J. E. Smerdon, D. A. Bishop, R. Seager, and J. S. Mankin, 2017: The 2016 southeastern US drought: An extreme departure from centennial wetting and cooling. J. Geophys. Res. Atmos., 122, 10 888-10 905, https://doi.org/ 10.1002/2017JD027523.

Xia, Y., and Coauthors, 2012a: Continental-scale water and energy flux analysis and validation for the North American Land Data Assimilation System project phase 2 (NLDAS-2): 1. Intercomparison and application of model products. J. Geophys. Res., 117, D03109, https://doi.org/10.1029/ 2011JD016048.

_- , and Coauthors, 2012b: Continental-scale water and energy flux analysis and validation for North American Land
Data Assimilation System project phase 2 (NLDAS-2): 2. Validation of model-simulated streamflow. J. Geophys. Res., 117, D03110, https://doi.org/10.1029/2011JD016051.

Yang, S., K. Lau, and K. Kim, 2002: Variations of the East Asian jet stream and Asian-Pacific-American winter climate anomalies. J. Climate, 15, 306-325, https://doi.org/10.1175/ 1520-0442(2002)015<0306:VOTEAJ > 2.0.CO;2.

Zhao, S., Y. Deng, and R. X. Black, 2018: An intraseasonal model of atmospheric variability relevant to the U.S. hydroclimate in boreal summer: Dynamic origin and East Asia connection. J. Climate, 31, 9855-9868, https://doi.org/ 10.1175/JCLI-D-18-0206.1.

Zhu, Z., and T. Li, 2016: A new paradigm for continental U.S. summer rainfall variability: Asia-North America teleconnection. J. Climate, 29, 7313-7327, https://doi.org/10.1175/ JCLI-D-16-0137.1. 